\title{
Rituximab in B-Cell Hematologic Malignancies: A Review of 20 Years of Clinical Experience
}

\author{
Gilles Salles (D) Martin Barrett · Robin Foà · Joerg Maurer • \\ Susan O'Brien · Nancy Valente · Michael Wenger · David G. Maloney
}

Received: July 14, 2017 / Published online: October 5, 2017

(C) The Author(s) 2017. This article is an open access publication

\begin{abstract}
Rituximab is a human/murine, chimeric anti-CD20 monoclonal antibody with established efficacy, and a favorable and well-defined safety profile in patients with various CD20-expressing lymphoid malignancies, including indolent and aggressive forms of B-cell non-Hodgkin lymphoma. Since its first approval 20 years ago, intravenously administered rituximab has revolutionized the
\end{abstract}

Enhanced content To view enhanced content for this article go to http://www.medengine.com/Redeem/ C80CF0607015D872.

\author{
G. Salles $(\bowtie)$ \\ Hématologie, Hospices Civils de Lyon and \\ Université de Lyon, Pierre-Bénite, Lyon, France \\ e-mail: gilles.salles@chu-lyon.fr \\ M. Barrett \\ Roche Products Ltd., Welwyn Garden City, UK \\ R. Foà \\ Department of Cellular Biotechnologies and \\ Hematology, Sapienza University, Rome, Italy \\ J. Maurer · M. Wenger \\ F. Hoffmann-La Roche Ltd., Basel, Switzerland \\ S. O’Brien \\ Chao Family Comprehensive Cancer Center, \\ University of California, Irvine, Orange, CA, USA \\ N. Valente \\ Genentech Inc., South San Francisco, CA, USA \\ D. G. Maloney \\ Fred Hutchinson Cancer Research Center, \\ Seattle, WA, USA
}

treatment of B-cell malignancies and has become a standard component of care for follicular lymphoma, diffuse large B-cell lymphoma, chronic lymphocytic leukemia, and mantle cell lymphoma. For all of these diseases, clinical trials have demonstrated that rituximab not only prolongs the time to disease progression but also extends overall survival. Efficacy benefits have also been shown in patients with marginal zone lymphoma and in more aggressive diseases such as Burkitt lymphoma. Although the proven clinical efficacy and success of rituximab has led to the development of other anti-CD20 monoclonal antibodies in recent years (e.g., obinutuzumab, ofatumumab, veltuzumab, and ocrelizumab), rituximab is likely to maintain a position within the therapeutic armamentarium because it is well established with a long history of successful clinical use. Furthermore, a subcutaneous formulation of the drug has been approved both in the EU and in the USA for the treatment of B-cell malignancies. Using the wealth of data published on rituximab during the last two decades, we review the preclinical development of rituximab and the clinical experience gained in the treatment of hematologic B-cell malignancies, with a focus on the well-established intravenous route of administration. This article is a companion paper to A. Davies, et al., which is also published in this issue.

Funding: F. Hoffmann-La Roche Ltd., Basel, Switzerland. 
Keywords: B-cell lymphoma; CD20; Chronic lymphocytic leukemia; Diffuse large B-cell lymphoma; Follicular lymphoma; Monoclonal antibody; Non-Hodgkin lymphoma; Rituximab; Safety; Treatment outcome

\section{INTRODUCTION}

Hematologic B-cell malignancies comprise a large, heterogeneous group of lymphoproliferative disorders that range from slow-growing, indolent non-Hodgkin lymphomas (NHLs), such as follicular lymphoma (FL) and chronic lymphocytic leukemia (CLL), to more aggressive forms of NHL, such as diffuse large B-cell lymphoma (DLBCL) [1, 2]. B-cell disorders represent more than $85 \%$ of all NHL cases [3]. In 2012, there were an estimated 385,700 new cases of NHL worldwide, with an estimated 199,700 patients dying from the disease [4], and evidence from US and UK statistics suggests that the annual incidence has been rising steadily since the 1970s [5, 6]. NHL incidence rates are higher among the elderly population than in the younger population, with diagnoses of NHL most common among patients aged 65-74 years [7], and a projection of population dynamics for CLL patients in the USA predicts that 199,000 patients will have the disease in 2025, partly driven by improved survival [8]. In view of the aging population worldwide, the diagnosis and treatment of B-cell hematologic malignancies are likely to remain an important focus for healthcare providers for the foreseeable future.

The treatment strategy for NHL is largely determined by histologic features, disease stage, patient age, prognosis, and the presence of comorbid disease. Staging is established using validated systems, which include the Ann Arbor staging classification for DLBCL [9] and FL [10], and the Binet and Rai staging systems for CLL [11]. Prognostic assessments at initial diagnosis are based on the International Prognostic Index (IPI) and age-adjusted IPI for DLBCL [9], the Follicular Lymphoma International Prognostic Index for FL [10], and the Mantle Cell Lymphoma International Prognostic Index for mantle cell lymphoma (MCL) [12]. In CLL, the Binet and Rai staging systems are both used to categorize patients into three groups according to their prognosis [11], and the International Prognostic Index for patients with CLL may also be applied [13]. In DLBCL, gene expression profiling can now be used to determine prognosis by identifying distinct disease subtypes according to their cell of origin $[14,15]$.

The development of monoclonal antibodies (mAbs) as a therapeutic treatment began in 1975 by researchers funded by the National Cancer Institute, César Milstein and Georges Köhler [16], who described the formation of hybridomas to rescue and produce a limitless supply of mAbs from a single B cell. For this work, Milstein and Köhler received the Nobel Prize for Physiology or Medicine in 1984 jointly with Niels Jerne [17]. Treatment with the first mAb occurred in 1980 [18], and this was followed by pioneering studies by Ron Levy's group at Stanford University, which produced patient-specific monoclonal anti-idiotype antibodies for treating lymphoma patients [19]. These studies proved the concept that mAbs could have a dramatic antitumor effect and that they were safe, but commercialization was limited by the fact they were patient specific. At the same time, antibodies were being used to investigate cell-surface proteins, resulting in the identification of B-cell-restricted antigens such as CD19 and CD20. This discovery paved the way for the production of therapeutic mAbs that could be used in patients whose tumors expressed those antigens. Given the widespread expression of CD20 on malignant B cells, treatment with a murine $\mathrm{mAb}$ against CD20 was undertaken [20], and demonstrated safety, albeit with limited clinical activity. This ultimately led to the development of a chimeric anti-CD20 $\mathrm{mAb}$ with increased antitumor activity; namely, rituximab.

Rituximab (MabThera ${ }^{\circledR} /$ Rituxan $^{\circledR} /$ Rituxan HYCELA $^{\mathrm{TM}}$, F. Hoffmann-La Roche Ltd.) is a human/murine chimeric, glycosylated immunoglobulin (Ig) G1- $\kappa$ mAb containing murine light- and heavy-chain variable region sequences, and human kappa and human IgG1 constant region sequences. Rituximab has specific affinity for the B-lymphocyte transmembrane protein, CD20, which is expressed on normal B cells (excluding stem cells, pro-B 
cells, and plasma B cells) and on most malignant B cells [21].

Intravenously administered rituximab was granted regulatory approval in 1997 by the US Food and Drug Administration and in 1998 by the European Medicines Agency for use in relapsed/refractory indolent NHL. Approvals for use in CLL followed in 2009 and 2010, respectively. Intravenously administered rituximab was the first therapeutic mAb to be used in the field of oncology, establishing a new class of anticancer drugs. Since its approval, rituximab has revolutionized the treatment of B-cell malignancies, becoming a standard component of care for FL [10, 22], DLBCL [9, 22], and CLL $[11,23]$. Rituximab has also been included in the WHO Model List of Essential Medicines since 2015 [24]. A new formulation of rituximab for subcutaneous administration has also been approved in the EU and USA for the treatment of patients with NHL and CLL, based primarily on the results of the SABRINA and SAWYER clinical trials $[25,26]$. Subcutaneously administered rituximab was developed primarily to simplify administration and shorten the administration time, and thus improve the patient experience by decreasing the burden of treatment. In addition, this may facilitate access to this important drug in resource-poor settings where intravenous administration may pose a particular challenge.

Clinical experience with intravenously administered rituximab in B-cell hematologic malignancies is extensive, currently extending to 20 years and to more than four million patient exposures worldwide, including data from an estimated 18,000 patients treated with rituximab in corporate-sponsored or supported clinical trials (Roche, data on file not publically available). Clinical experience with rituximab also extends to off-label use in MCL, for which rituximab is a standard component of care [27], and in other hematologic malignancies, including marginal zone lymphoma, Hodgkin lymphoma, Burkitt lymphoma, and B-lineage acute lymphoblastic leukemia (see "Clinical Efficacy of Rituximab"), as well as to nonhematologic licensed indications, including rheumatoid arthritis, and granulomatosis with polyangiitis and microscopic polyangiitis
[28-30], which are outside the scope of this review.

This article reviews the preclinical development of rituximab and clinical experience with the intravenous formulation in B-cell hematologic malignancies. Discussion of the preclinical and clinical experience with subcutaneously administered rituximab is outside the scope of this review, but is covered extensively in a recent publication by Davies et al. [31].The information reported in this article is derived from previously conducted studies, and does not include any new studies of human or animal subjects performed by any of the authors.

\section{MECHANISM OF ACTION OF RITUXIMAB}

Rituximab binds with high affinity and specificity to the CD20 antigen, which is expressed on the vast majority of malignant $B$ cells. The apparent affinity constant of rituximab for human CD20, as determined by Scatchard analysis using a human lymphoblastoid cell line (SB), is approximately $5.2 \mathrm{nmol} / \mathrm{L}$ [32]. The characteristics of rituximab binding to the CD20 molecule led to the definition of the "type I" anti-CD20 mAbs, which share several properties and are distinct from type II mAbs such as obinutuzumab. At least four mechanistic pathways are thought to be responsible for the elimination of $\mathrm{CD}_{2} \mathrm{O}^{+}$cells by rituximab (Fig. 1): antibody-dependent cellular cytotoxicity (ADCC), antibody-dependent cellular phagocytosis, complement-dependent cytotoxicity (CDC), and direct antitumor effects via either apoptosis or other cell death pathways [33-36]. Binding of the fragment crystallizable (Fc) portion of the rituximab $\mathrm{mAb}$ to tumor cells results in the reorganization of CD20 molecules into lipid rafts and subsequent activation of the classical pathway of the complement cascade. This leads to CDC, including tumor cell lysis and augmentation of phagocytosis. ADCC occurs as a result of an interaction between the Fc portion of rituximab in antibody-coated tumor cells and membrane-bound Fc $\gamma$ receptors expressed on the surface of 


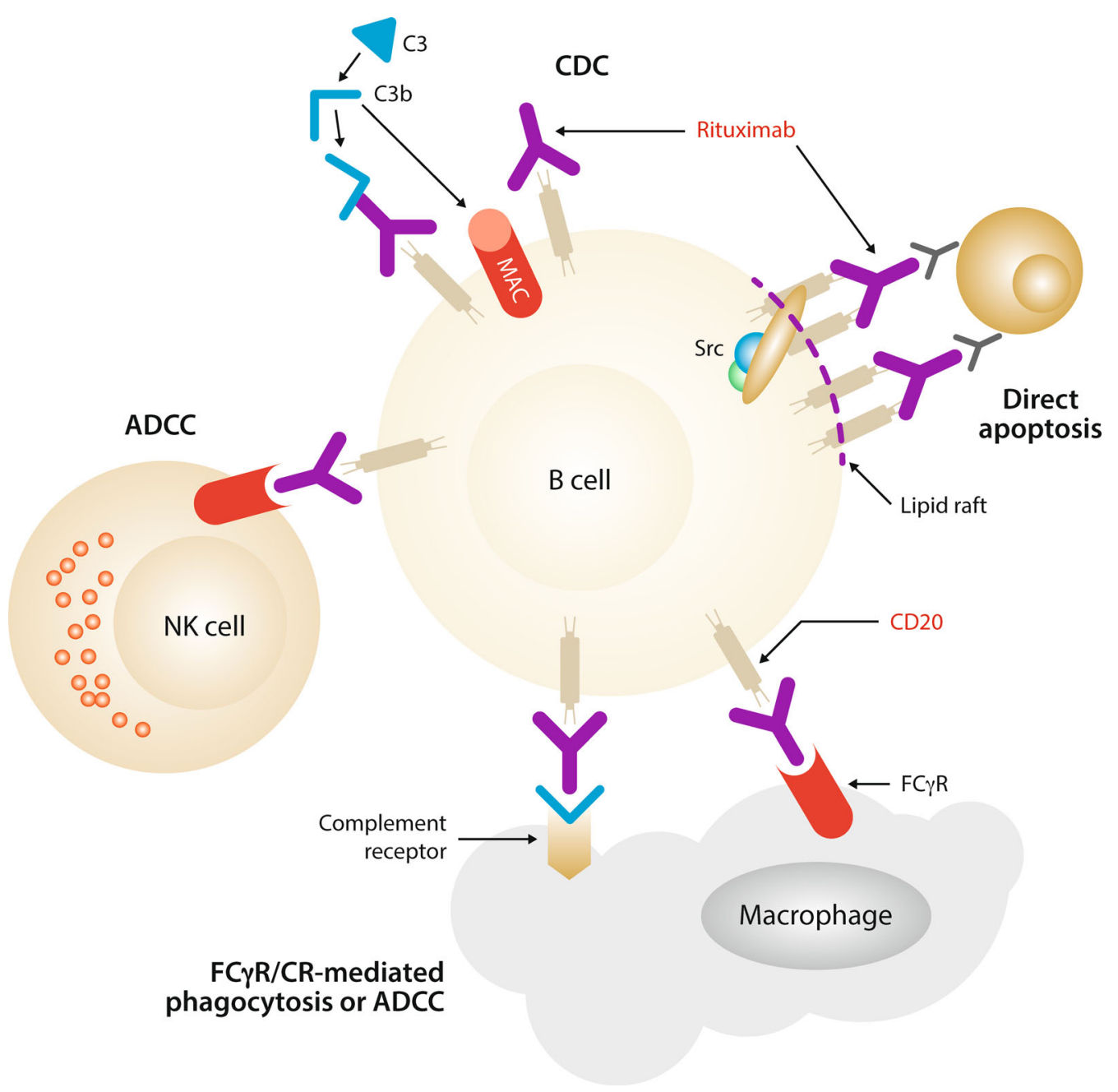

Fig. 1 Mechanisms of rituximab-mediated cell death. Rituximab-coated B cells are killed by at least four different mechanisms: (1) binding of rituximab to CD20 on the B-cell surface causes activation of the complement cascade, which generates the membrane attack complex (MAC), which can directly induce B-cell lysis by complement-dependent cytotoxicity (CDC). (2) Binding of rituximab allows interaction with natural killer (NK) cells via $\mathrm{Fc}$ receptors (FcRs) III, which leads to antibody-dependent cellular cytotoxicity (ADCC). (3) The Fc portion of rituximab and the deposited complement fragments

effector cells (natural killer cells, granulocytes, and macrophages) [37]. This interaction triggers the onset of cellular immune responses central to ADCC, including the release of cytokines, chemokines, and mediators that kill target cells. allow recognition by both FcRs and complement receptors on macrophages, which leads to phagocytosis and ADCC. (4) The crosslinking of several molecules of rituximab and CD20 in the lipid raft determines the interaction of these complexes with elements of a signaling pathway involving Src kinases that mediate direct apoptosis. FCR Fc receptor, $\mathrm{FC} \gamma \mathrm{R}$ Fc $\gamma$ receptor. (Republished with permission of the American Society of Hematology from Jaglowski et al. [166]; permission conveyed through the Copyright Clearance Center)

In addition, rituximab binding to $\mathrm{CD} 20$ on $\mathrm{B}$ lymphocytes is thought to induce cell death via nonclassical apoptosis by triggering the crosslinking of multiple CD20 molecules [34-36]. 


\section{PHARMACODYNAMICS OF RITUXIMAB}

Potent B-cell-depleting activity in peripheral blood and lymphoid tissues was reported with rituximab in phase I and phase II studies $[38,39]$. Circulating $\mathrm{CD} 20^{+} \mathrm{B}$ cells underwent rapid depletion in the peripheral blood of patients with recurrent B-cell lymphoma treated with a single dose of rituximab. This effect was dose dependent and persisted for at least 23 months in most patients. In addition, there was evidence of a fall in the number of B cells in lymph node biopsy samples 2 weeks after administration of rituximab compared with pretreatment [38]. In a second group of patients with relapsed low-grade NHL treated with multiple doses of rituximab, B-cell depletion was maintained until nearly 6 months after treatment, followed by a slow recovery [39].

\section{PHARMACOKINETIC PROFILE OF RITUXIMAB}

The pharmacokinetic (PK) profile of rituximab in a variety of B-cell malignancies has been characterized throughout the product's life cycle, with use of original data from clinical studies as described herein, and by integration of these data into population PK analyses.

Among patients with low-grade or follicular NHL treated with intravenously administered rituximab, serum concentrations of rituximab were detectable after the first infusion and increased with subsequent administrations [38-40]. In 203 patients with relapsed low-grade lymphoma who received four weekly intravenous infusions of rituximab $\left(375 \mathrm{mg} / \mathrm{m}^{2}\right)$ in two clinical studies $[39,40]$, the mean maximum plasma concentration $\left(C_{\max }\right)$ of rituximab was $486 \mu \mathrm{g} / \mathrm{mL}$ (range $77.5-996.6 \mu \mathrm{g} / \mathrm{mL}$ ) after the fourth dose, and the drug was detectable in serum for up to 6 months after completion of dosing $[29,30]$. In another study, the median serum rituximab concentration after the last of four weekly infusions in a group of $22 \mathrm{FL}$ patients with low tumor burden was approximately $380 \mu \mathrm{g} / \mathrm{mL}$, and the study authors predicted a steady-state plasma concentration in this group of $438 \mu \mathrm{g} / \mathrm{mL}$ if the drug had been administered once weekly for 8 weeks [41].

Elimination of rituximab in patients with B-cell malignancies is target mediated (i.e., binding of the drug to CD20 on B cells clears the antibody from the serum during the initial infusions, leading to a reduction in or saturation of accessible CD20-binding sites at lymph nodes). This was seen in the phase III study by Berinstein et al. [40], which found a marked increase in mean elimination half-life $\left(t_{1 / 2}\right)$ from 76.3 to $205.8 \mathrm{~h}$ from the first to the fourth rituximab infusion, which corresponded to a nearly fourfold decrease in clearance (from 38.2 to $9.2 \mathrm{~mL} / \mathrm{h}$ ) and an increase in rituximab $C_{\max }$ from 205.6 to $464.7 \mu \mathrm{g} / \mathrm{mL}$. Later studies reported even slower clearance (i.e., $t_{1 / 2}$ for rituximab of approximately 3 weeks), although with large intersubject variability $[41,42]$; total systemic clearance was estimated at $3.1-11.9 \mathrm{~mL} / \mathrm{h} / \mathrm{m}^{2}$ in the earlier study [41].

No notable differences were observed between the PK profiles of rituximab when it was administered as monotherapy and when rituximab therapy was combined with cyclophosphamide, doxorubicin, vincristine, and prednisone (CHOP) chemotherapy [43]. A population PK analysis in 298 patients with NHL from six clinical studies who were treated with rituximab alone or rituximab combined with CHOP (R-CHOP) showed that age, sex, race, and WHO performance status had no effect on rituximab pharmacokinetics [44]. Higher B-cell counts and greater baseline tumor burden were associated with increased clearance rates, and the volume of distribution varied depending on body surface area and CHOP chemotherapy. Rituximab elimination was reduced following multiple infusions. This analysis found that the PK profile of rituximab in NHL patients is best described by a two-compartment model with a nonspecific time-independent clearance component and a time-dependent clearance component exhibiting first-order kinetics [44].

In a population PK analysis in previously treated patients with relapsed or refractory CLL treated with rituximab $\left(375 \mathrm{mg} / \mathrm{m}^{2}\right.$ in cycle 1 then $500 \mathrm{mg} / \mathrm{m}^{2}$ in cycles 2-6) and 
standard-dose fludarabine and cyclophosphamide (FC), PK data for rituximab in 21 patients showed a time-dependent PK profile with wide interpatient variability [45]. The study authors noted differences in PK parameters in these CLL patients compared with patients with NHL from a previous population analysis [44]: CLL patients had faster clearance (1260 mL/day vs $585 \mathrm{~mL} /$ day), a larger volume of distribution (central $4150 \mathrm{~mL}$ vs $2700 \mathrm{~mL}$, peripheral $2320 \mathrm{~mL}$ vs $1500 \mathrm{~mL}$ ), and a lower rate of change from the target-mediated clearance pathway (via CD20) to catabolic elimination (via IgG1) compared with NHL patients [45].

Rituximab serum concentrations have been reported to correlate with clinical response. In a detailed analysis of 166 patients with low-grade or follicular NHL, median serum concentrations of rituximab were higher in responders than in nonresponders after each of the four weekly infusions and up to 3 months after treatment (e.g., 502.8 and $412.4 \mu \mathrm{g} / \mathrm{mL}$, respectively, after the fourth infusion; $P=0.01$ ) [40]. There was an inverse relationship between serum rituximab concentrations and baseline tumor burden indicators. Linear regression showed the inverse correlation between absolute levels of circulating peripheral $\mathrm{B}$ cells at the baseline and rituximab concentration to be statistically significant from the second infusion until 1 month after treatment. Inverse correlations between rituximab concentrations in serum and (1) the maximum diameter of the largest lesion and (2) the sum of the product of the perpendicular diameters of the six largest lesions were statistically significant at all time points measured with the exception of the period following the first infusion.

A similar relationship between exposure and response was seen in a phase II study of 68 Japanese patients with aggressive B-cell lymphoma [46]. Serum rituximab concentrations were evaluated in seven responders and five nonresponders. The mean ( \pm standard deviation) trough levels and areas under curves of serum antibody concentration versus time (AUC) for responders and nonresponders were $59.7 \pm 11.4$ and $43.0 \pm 6.4 \mu \mathrm{g} / \mathrm{mL}$, respectively, and $608,585 \pm 147,373$ and $383,053 \pm$
$176,903 \mu \mathrm{g} \mathrm{h} / \mathrm{mL}$, respectively, with significant differences between groups $(P=0.021$ and $P=0.037$ ). Pretreatment tumor size (sum of the product of the perpendicular diameters) was inversely correlated with AUC $(P<0.05$ by Spearman's rank correlation coefficient).

Other studies have shown that rituximab exposure falls as tumor volume increases, and that higher exposure correlated with better response and/or outcome [47-50]. A recent report from Tout et al. [50] in 108 previously untreated DLBCL patients demonstrated that rituximab exposure decreased as baseline total metabolic tumor volume increased, with a high AUC in cycle 1 being associated with better PET response after cycle 4 (odds ratio 5.56, $P=0.0006)$ and longer progression-free-survival (PFS; hazard ratio, $\mathrm{HR}, 0.38, P=0.011$ ) and overall survival (OS; HR 0.17, $P=0.001$ ). Sex and body weight may also influence rituximab pharmacokinetics $[51,52]$. In a study of 20 elderly patients (aged 61-79 years) with DLBCL, Müller et al. [51] found that rituximab clearance was reduced and $t_{1 / 2}$ increased in women compared with men. In addition, the volume of distribution increased by $0.1 \mathrm{~L} / \mathrm{kg}$ for body weights greater than $75 \mathrm{~kg}$. Although the benefit from addition of rituximab to chemotherapy is similar in younger male and female patients, this does not seem to hold true for older patients, with elderly female patients benefitting more than elderly male patients [52]. Swedish registry data have shown similar patterns, with possibly inadequate dosing in younger female patients, and male patients of all ages [53].

\section{MANUFACTURE OF RITUXIMAB}

Rituximab is produced in suspension culture by a Chinese hamster ovary transfectoma containing the TCAE 8 expression vector in a nutrient medium. Process and product impurities such as high molecular weight aggregates are then removed by protein A affinity chromatography and anion exchange chromatography. The purified rituximab is then formulated as an aqueous concentrate for intravenous administration under sterile conditions, in a 
mixture of sodium chloride $(9.0 \mathrm{mg} / \mathrm{mL})$, polysorbate $80 \quad(0.7 \mathrm{mg} / \mathrm{mL})$, sodium citrate dihydrate $(7.35 \mathrm{mg} / \mathrm{mL}$ ), and water (solution $\mathrm{pH}$ 6.5 , rituximab concentration $10 \mathrm{mg} / \mathrm{mL}$ ), and packaged in 10- or 50-mL borosilicate glass vials. As the vials are designed for single use, no preservatives are added to the formulation. An unopened vial has a shelf life of 30 months when stored at the recommended temperature of $2-8^{\circ} \mathrm{C}$.

\section{CLINICAL EFFICACY OF RITUXIMAB}

\section{Rituximab in Follicular Lymphoma}

The initial regulatory approval of rituximab in 1997 in FL was based on data from a pivotal phase II trial of rituximab monotherapy in 166 patients with relapsed or refractory low-grade NHL. The overall response rate (ORR) in this trial was $48 \%$ [complete response (CR) rate 6\%], and the median time to progression for the intent-to-treat population was 13.0 months [54]. Several other trials published between 1997 and 2000 showed similar results in relapsed/refractory low-grade NHL, with overall tumor response rates ranging from $38 \%$ to $47 \%$ after 4 weeks' treatment with rituximab [55-57], and $57 \%$ after 8 weeks' treatment [58]. Each of these studies involved between 30 and 70 patients.

More recently, a $74 \%$ ORR and a $28 \%$ CR rate, with median PFS of 23.5 months and $91.7 \%$ OS rate after 7 years of follow-up, were reported in 46 patients with low tumor burden disease after first-line induction therapy with four weekly doses of rituximab at $375 \mathrm{mg} / \mathrm{m}^{2}$ [59]. Two phase III studies in larger numbers of patients have also shown activity of rituximab monotherapy. Taverna et al. [60] reported a $16.9 \% \mathrm{CR} /$ unconfirmed CR rate in 261 patients undergoing induction therapy with four doses of rituximab (this study included patients with previously untreated and relapsed/refractory disease). Subsequent short-term (four doses; $n=82$ ) or long-term (5 years or less; $n=83$ ) rituximab maintenance therapy yielded median event-free survival (EFS) of 3.4 and 5.3 years, respectively $(P=0.14)$. In a trial in patients with advanced disease receiving four doses of rituximab alone $(n=156)$ or in conjunction with interferon alfa $(n=157)$ [61], there was a $78 \%$ ORR to an initial cycle of treatment. Responders who received a second cycle showed CR/unconfirmed CR rates of $21 \%$ and $41 \%$, respectively $(P=0.005)$. The median times to treatment failure were 28 and 21.5 months, respectively $(P=0.302)$.

Since then, substantial clinical benefit has been reported in FL patients from the incorporation of rituximab into induction chemotherapy regimens in both the first-line setting [62-70] and in previously treated patients $[62,71]$.

Induction treatment with rituximab and chemotherapy has been shown to be superior to chemotherapy alone in several large-scale trials (typical treatment duration of 6 months), mainly conducted in previously untreated patients with stage III/IV FL, consistently achieving better results in terms of ORR, CR, time to treatment failure, PFS, and OS (Table 1). A variety of chemotherapy regimens were combined with rituximab therapy in these studies, including $\mathrm{CHOP}$, cyclophosphamide, vincristine, and prednisolone (CVP), and mitoxantrone, chlorambucil, and prednisone (MCP) regimens. On the basis of the body of evidence provided by these studies, rituximab therapy plus chemotherapy has been adopted worldwide as the standard of care for the firstline treatment of patients with FL [10, 22], and the worldwide indications for rituximab are reflective of this.

The use of rituximab maintenance therapy to preserve responses to induction therapy in responding patients, and to further enhance clinical outcomes, has also been demonstrated in previously untreated patients with advanced FL, as demonstrated in the Eastern Cooperative Oncology Group (ECOG) 1496 and PRIMA trials [72-74]. In these two studies, previously untreated patients with advanced FL who had responded to either CVP (ECOG 1496) or one of three rituximab-chemotherapy induction treatment regimens [rituximab plus CVP, RCHOP, or rituximab plus fludarabine, cyclophosphamide, and mitoxantrone (R-FCM); PRIMA] were randomized to receive rituximab 
Table 1 Summary of key studies evaluating rituximab-based immunochemotherapy in patients with previously untreated or relapsed/refractory follicular lymphoma

\begin{tabular}{|c|c|c|c|c|c|c|}
\hline Study reference & $\begin{array}{l}\text { Line of therapy } \\
\text { and no. of } \\
\text { patients }\end{array}$ & $\begin{array}{l}\text { Treatment } \\
\text { regimen }\end{array}$ & ORR & CR & $\begin{array}{l}\text { PFS, EFS, or other } \\
\text { parameter as } \\
\text { indicated }^{\mathrm{a}}\end{array}$ & OS \\
\hline $\begin{array}{l}\text { GLLSG } \\
\text { Hiddemann et al. } \\
\text { [63] }\end{array}$ & 1L (428) & $\begin{array}{l}\text { R-CHOP vs } \\
\text { CHOP }\end{array}$ & $\begin{array}{r}96 \% \text { vs } \\
90 \%{ }^{b}\end{array}$ & $\begin{array}{c}20 \% \text { vs } \\
17 \%\end{array}$ & $\begin{array}{l}\text { TF (median } \\
\text { observation time } \\
18 \text { months): } \\
12.6 \% \text { vs } 29.8 \%^{\mathrm{b}}\end{array}$ & $\begin{array}{l}\text { Deaths: } \\
2.7 \% \text { vs } \\
8.3 \%^{\mathrm{b}}\end{array}$ \\
\hline $\begin{array}{l}\text { East German Study } \\
\text { Group }\end{array}$ & $1 \mathrm{~L}(201)$ & R-MCP vs MCP & $\begin{array}{r}92 \% \text { vs } \\
75 \%{ }^{b}\end{array}$ & $\begin{array}{r}50 \% \text { vs } \\
25 \%{ }^{\mathrm{b}}\end{array}$ & $\begin{array}{l}\text { EFS: NR vs } \\
26 \text { months }\end{array}$ & $\begin{array}{l}\text { 4-year: } 87 \% \\
\text { vs } 74 \%{ }^{\mathrm{b}}\end{array}$ \\
\hline Herold et al. [64] & & & & & $\begin{array}{l}\text { PFS: NR vs } \\
28.8 \text { months }^{\text {b }} \\
\text { mFU: } 47 \text { months }\end{array}$ & \\
\hline $\begin{array}{l}\text { Marcus et al. [65] } \\
\text { Marcus et al. [66] }\end{array}$ & $1 \mathrm{~L}(321)$ & $\mathrm{R}-\mathrm{CVP}$ vs CVP & $\begin{array}{r}81 \% \text { vs } \\
57 \%{ }^{\mathrm{b}}\end{array}$ & $\begin{array}{r}41 \% \text { vs } \\
10 \%{ }^{b}\end{array}$ & $\begin{array}{l}\text { TTF: } 27 \text { months vs } \\
7 \text { months }^{\mathrm{b}} \\
\text { DFS: NR vs } \\
21 \text { months }^{\mathrm{b}} \\
\text { mFU: } 30 \text { months }\end{array}$ & $\begin{array}{c}\text { 4-year: } 83 \% \\
\text { vs } 77 \%^{\mathrm{b}}\end{array}$ \\
\hline $\begin{array}{l}\text { GELA-GOELAMS } \\
\text { FL2000 } \\
\text { Salles et al. [67] } \\
\text { Bachy et al. [68] }\end{array}$ & $1 \mathrm{~L}(358)$ & $\begin{array}{l}\text { R-CHVP + INF } \\
\text { vs } \\
\text { CHVP + INF }\end{array}$ & $\begin{array}{r}81 \% \text { vs } \\
72 \%{ }^{b}\end{array}$ & $\begin{array}{r}51 \% \text { vs } \\
39 \%{ }^{b}\end{array}$ & $\begin{array}{l}\text { EFS: } 5.5 \text { years vs } \\
2.8 \text { years }^{\text {b }} \\
\text { 5-year EFS: } 53 \% \text { vs } \\
37 \%^{\text {b }} \\
\text { 8-year EFS: } 44 \% \text { vs } \\
28 \%^{\text {b }} \\
\text { mFU: } 5 \text { and } 8.3 \text { years }\end{array}$ & $\begin{array}{c}\text { 5-year: } 84 \% \\
\text { vs } 79 \% \\
8 \text {-year: } 79 \% \\
\text { vs } 70 \%\end{array}$ \\
\hline $\begin{array}{l}\text { FOLL05 } \\
\text { Federico et al. [69] }\end{array}$ & $1 \mathrm{~L}(504)$ & $\begin{array}{l}\text { R-CVP vs } \\
\text { R-CHOP } \\
\text { vs R-FM }\end{array}$ & $\begin{array}{l}88 \% \text { vs } \\
93 \% \text { vs } \\
91 \%\end{array}$ & $\begin{array}{l}67 \% \text { vs } \\
73 \% \text { vs } \\
72 \%\end{array}$ & $\begin{array}{l}\text { 3-year TF: } 46 \% \text { vs } \\
\text { 62\% vs } 59 \% \\
\text { HR 0.62, R-CHOP } \\
\text { vs R-CVP }{ }^{\mathrm{b}, \mathrm{c}}, \mathrm{HR} \\
0.63, \mathrm{R}-\mathrm{FM} \text { vs } \\
\text { R-CVP } \\
\text { 3-year PFS: } 52 \% \text { vs } \\
\text { 68\% vs } 63 \% \\
\text { HR 0.64, R-CHOP } \\
\text { vs R-CVP } \\
\text { 0.66, R-FM vs } \\
\text { R-CVP } \\
\text { mFU: } 34 \text { months }\end{array}$ & $\begin{array}{l}\text { 3-year: } 95 \% \\
\text { (all } \\
\text { patients) }\end{array}$ \\
\hline
\end{tabular}


Table 1 continued

\begin{tabular}{|c|c|c|c|c|c|c|}
\hline Study reference & $\begin{array}{l}\text { Line of therapy } \\
\text { and no. of } \\
\text { patients }\end{array}$ & $\begin{array}{l}\text { Treatment } \\
\text { regimen }\end{array}$ & ORR & CR & $\begin{array}{l}\text { PFS, EFS, or other } \\
\text { parameter as } \\
\text { indicated }^{\text {a }}\end{array}$ & OS \\
\hline Rummel et al. [70] & $\begin{array}{l}\text { 1L (514: } 420 \\
\text { NHL, } \\
\text { including } 279 \\
\text { FL; } 94 \mathrm{MCL})\end{array}$ & $\begin{array}{c}\mathrm{R}+\text { benda vs } \\
\mathrm{R}-\mathrm{CHOP}\end{array}$ & $\begin{array}{c}93 \% \text { vs } \\
91 \%\end{array}$ & $\begin{array}{r}40 \% \text { vs } \\
30 \%{ }^{b}\end{array}$ & $\begin{array}{l}\text { PFS: } 69.5 \text { months vs } \\
31.2 \text { months } \\
\text { (HR 0.58) } \\
\text { mFU: } 45 \text { months }\end{array}$ & $\begin{array}{l}\text { Deaths: } \\
\text { 16.5\% vs } \\
17.8 \%\end{array}$ \\
\hline $\begin{array}{l}\text { Czuczman et al. } \\
\text { [62] }\end{array}$ & $1 \mathrm{~L}$ and $2 \mathrm{~L}(38)$ & R-CHOP & $\begin{array}{l}100 \%(1 \mathrm{~L} \\
100 \% \\
\mathrm{R} / \mathrm{R} \\
100 \%)^{\mathrm{d}}\end{array}$ & $\begin{array}{c}87 \%(1 \mathrm{~L} \\
90 \% \\
\mathrm{R} / \mathrm{R} \\
78 \%)^{\mathrm{d}}\end{array}$ & $\begin{array}{l}\text { TTP: } 82.3 \text { months } \\
\text { mFU: NA }\end{array}$ & \\
\hline $\begin{array}{l}\text { EORTC } 20981 \\
\text { van Oers et al. [71] }\end{array}$ & $\mathrm{R} / \mathrm{R}(465)$ & $\begin{array}{l}\text { R-CHOP vs } \\
\text { CHOP }\end{array}$ & $\begin{array}{r}85.1 \% \text { vs } \\
72.3 \%^{\mathrm{b}}\end{array}$ & $\begin{array}{r}29.5 \% \text { vs } \\
15.6 \%{ }^{b}\end{array}$ & $\begin{array}{l}\text { PFS: } 33.1 \text { months vs } \\
20.2 \text { months } \\
\quad\left(\text { HR } 0.65^{\mathrm{b}}\right) \\
\text { mFU: } 39.4 \text { months }\end{array}$ & $\begin{array}{l}\text { 3-year: } \\
\text { 82.5\% vs } \\
71.9 \% \\
(\mathrm{HR} \\
0.74)\end{array}$ \\
\hline
\end{tabular}

All studies were phase III randomized trials except for the study of Czuczman et al. [62], which was a single-arm phase II study

benda bendamustine, CHOP cyclophosphamide, doxorubicin, vincristine, and prednisone, CHVP cyclophosphamide, doxorubicin, etoposide, and prednisone, $C R$ complete response, $C V P$ cyclophosphamide, vincristine, and prednisone, $D F S$ disease-free survival, EFS event-free survival, EORTC European Organisation for Research and Treatment of Cancer, FL follicular lymphoma, FM fludarabine and mitoxantrone, GELA Groupe d'Etude des Lymphomes de l'Adulte, GLLSG German Low-Grade Lymphoma Study Group, GOELAMS Groupe Ouest Est des Leucémies et Autres Maladies du Sang, $H R$ hazard ratio, $I N F$ interferon, $I L$ first line, $2 L$ second line $M C L$ mantle cell lymphoma, $M C P$ mitoxantrone, chlorambucil, and prednisone, $m F U$ median follow-up, $N A$ not available, $N H L$ non-Hodgkin lymphoma, $N R$ not reached, $O R R$ overall response rate, $O S$ overall survival, $P F S$ progression-free survival, $R$ rituximab, $R / R$ relapsed/refractory, $T F$ treatment failure, TTF time to treatment failure, TTP time to progression

a Median values

b Statistically significant difference

c HR adjusted by Follicular Lymphoma International Prognostic Index 0-2 vs 3-5

${ }^{\mathrm{d}}$ Updated values assessed according to International Workshop response criteria

maintenance therapy for 2 years or observation. In the ECOG 1496 study, rituximab maintenance therapy achieved a significantly higher 3 -year PFS rate than observation (64\% vs 33\%; HR $0.4, P<0.001)$ [72]. OS at 3 years was, however, comparable between the two arms (91\% vs $86 \%$; HR 0.6, $P=0.08$ ). In the PRIMA trial, the 3-year PFS rate was $74.9 \%$ in the rituximab maintenance therapy arm compared with $57.6 \%$ for patients randomized to undergo observation (HR 0.55, P<0.001) [73], and long-term follow-up (median of 73 months) showed that the PFS benefit achieved with rituximab maintenance therapy was maintained after 6 years $(59.2 \%$ vs $42.7 \%$; HR 0.58 , $P<0.0001$ ) [74]. Six-year OS in the PRIMA trial was favorable with both rituximab maintenance therapy and observation, and did not differ significantly between the two arms. Neither median PFS nor median OS had been reached in the rituximab maintenance therapy arm at the 6-year follow-up.

The RESORT trial compared the efficacy of rituximab maintenance therapy with rituximab 
retreatment in 545 patients with previously untreated FL and a low tumor burden [75]. The study found no difference between groups in terms of the primary end point, time to treatment failure (this outcome measure was defined as a lack of response to rituximab retreatment), time to progression of less than 26 weeks, commencement of alternative treatment, or an inability to complete planned treatment [75]. The lack of a significant benefit of rituximab maintenance therapy over rituximab retreatment may have been because the primary end point favored the retreatment arm or because the study was conducted in patients with low tumor burden, in contrast to the PRIMA study [73, 74], which was conducted in patients requiring treatment.

Similarly, in the relapsed/refractory FL setting, significant improvements in efficacy have been reported with rituximab induction therapy plus chemotherapy and rituximab maintenance therapy compared with standard chemotherapy (Table 2) [71, 76-79]. For example, superior outcomes were reported with R-FCM compared with fludarabine, cyclophosphamide, and mitoxantrone (FCM) in patients with relapsed/refractory FL or MCL enrolled in a phase III study conducted by the German Low-Grade Lymphoma Study Group [76]. In all study patients, the addition of rituximab to FCM induction therapy significantly increased ORR (79\% vs $58 \% ; P=0.01)$, median PFS (16 months vs 10 months; $P=0.04$ ), and median OS (not reached vs 24 months; $P<0.01$ ) compared with FCM alone [76]. A second randomization, to rituximab maintenance therapy or observation in patients who had responded to induction therapy, showed a significant prolongation of response duration with maintenance treatment (median, not reached vs 17 months; $P<0.001$ ) [77]. The phase III European Organisation for Research and Treatment of Cancer 20981 trial included an induction phase during which patients with relapsed/refractory FL were randomized to receive R-CHOP or CHOP, followed by randomization to rituximab maintenance therapy or observation for those patients who responded to induction therapy [71, 78]. The study investigators reported a significant increase in ORR ( $85 \%$ vs $72 \%$;
$P<0.001) \quad$ and $\quad$ PFS $\quad(33.1$ months vs 20.2 months; HR $0.65, P<0.001)$, and a trend toward an increase in 3 -year OS rate $(83 \%$ vs $72 \%$; HR 0.74, $P=0.096$ ) with R-CHOP compared with CHOP induction therapy. Rituximab maintenance therapy subsequently achieved a significant improvement in median PFS compared with observation (51.5 months vs 14.9 months; HR 0.40, $P<0.001$ ); the 5-year OS rate was also greater with rituximab maintenance therapy (74\% vs $65 \%$; HR $0.70, P=0.07$ ), but the difference between the two arms did not achieve statistical significance. The investigators cited the unbalanced use of rituximab in postprotocol salvage treatment as a possible reason for this finding [78]. A similar pattern of results was reported in the phase III SAKK 35/98 trial evaluating induction therapy with single-agent rituximab followed by rituximab maintenance therapy or observation (Table 2) [79], further confirming the benefit of rituximab maintenance therapy in patients with relapsed/refractory FL. In a meta-analysis of data from 2315 patients in seven randomized trials, survival was significantly improved with rituximab maintenance therapy compared with observation only (HR 0.79, 95\% confidence interval 0.66-0.96) for all categories of patients except those receiving first-line therapy that included rituximab induction therapy [80].

Watchful waiting until disease progression occurs has conventionally been used in FL patients with advanced disease with low tumor burden [81]. The use of rituximab in this setting to delay the need for chemotherapy or radiotherapy was explored in a multinational phase III study in 463 patients who underwent watchful waiting, rituximab induction therapy (375 mg/m² weekly for 4 weeks), or rituximab induction therapy followed by 2 years' maintenance therapy [82]. Of the patients in the watchful waiting group, $46 \%$ had not needed new treatment at 3 years, compared with $88 \%$ in the rituximab maintenance therapy group (HR 0.21, $P<0.0001$ ). Significantly more patients in the induction therapy group than in the watchful waiting group (78\%) had not needed new treatment at 3 years (HR 0.35, $P<0.0001)$, whereas the proportion not needing new treatment was similar in the 


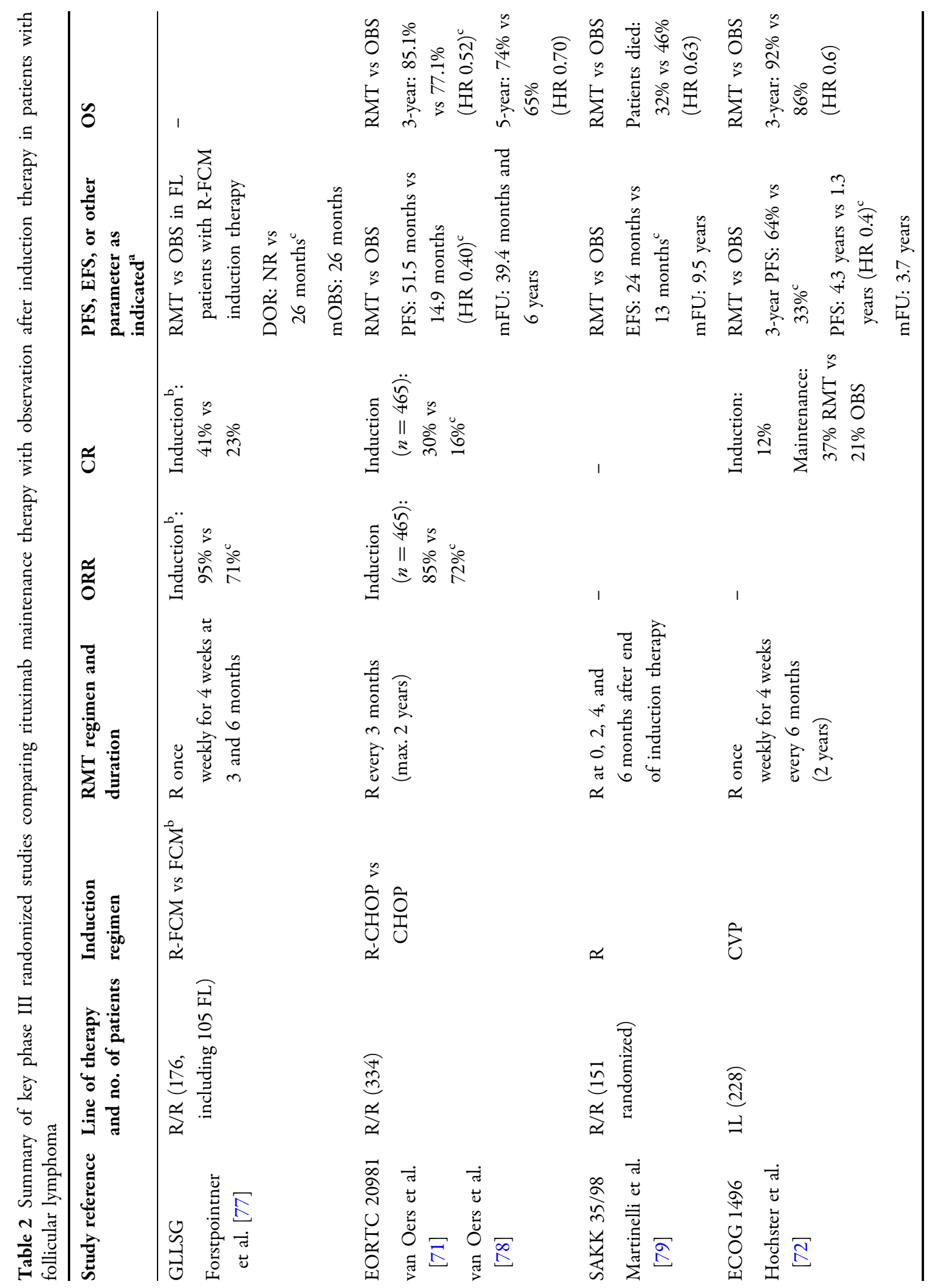




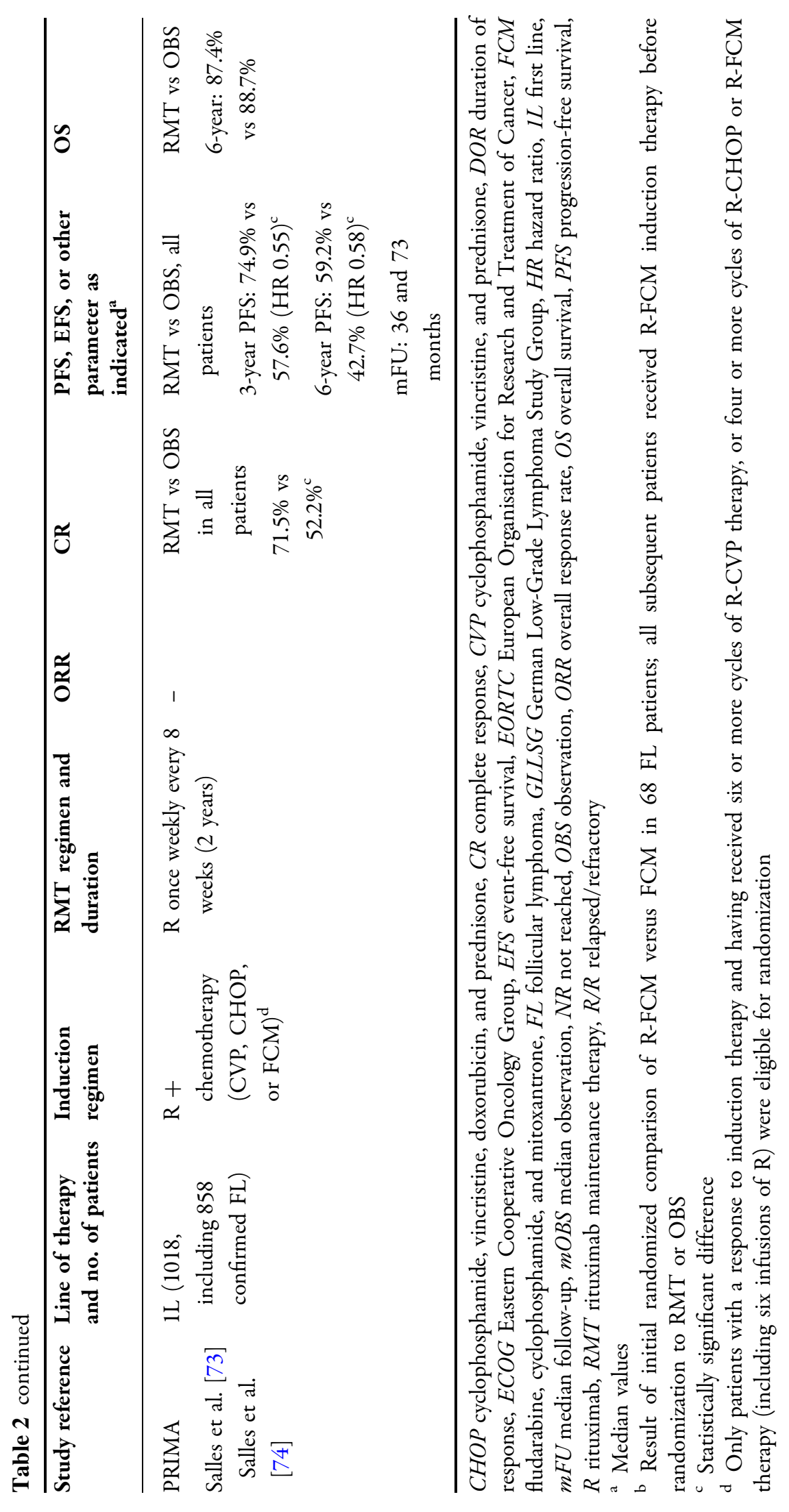


maintenance therapy and induction therapy groups (HR 0.75, $P=0.33$ ). The place of rituximab therapy relative to watchful waiting in FL remains under discussion in the literature [83].

\section{Rituximab in Diffuse Large B-Cell Lymphoma}

Rituximab is currently approved in Europe and the USA for previously untreated CD20 ${ }^{+}$DLBCL in combination with $\mathrm{CHOP}$ or other anthracycline-based chemotherapy and is also included in current treatment guidelines in combination with salvage chemotherapy for relapsed/refractory disease $[9,22]$. A phase II trial of R-CHOP as first-line treatment in patients with aggressive NHL (67\% with DLBCL) was the first study to demonstrate the feasibility and safety of RCHOP in this population, with an ORR of $94 \%$ and 20 of 33 patients (61\%) having a CR [84].

Two pivotal phase III randomized trials established R-CHOP therapy as the standard of care for elderly patients with DLBCL $[85,86]$ (Table 3). In a study conducted by the Groupe d'Etude des Lymphomes de l'Adulte (GELA; LNH98-5), previously untreated elderly patients (aged 60-80 years) with DLBCL were randomized to receive eight cycles of $\mathrm{R}-\mathrm{CHOP}$ or $\mathrm{CHOP}$ therapy [85]. Sixty percent of patients were deemed to be poor risk, with age-adjusted IPI scores of 2 or 3 . The CR rate was significantly higher in favor of R-CHOP (76\% vs $63 \%$; $P=0.005)$. The proportions of patients with EFS (disease progression or relapse, institution of new treatment, or any-cause death) at 2 years ( $57 \%$ vs $38 \%$; HR $0.58, P<0.001)$ and OS at 2 years $(70 \%$ vs $57 \%$; HR $0.64, P=0.007$ ) also favored RCHOP. In a second phase III study (ECOG 4494/ US Intergroup study), DLBCL patients aged 60 years or older were randomized to receive $\mathrm{R}$ $\mathrm{CHOP}$ or $\mathrm{CHOP}$, followed by a second randomization for responding patients to rituximab maintenance therapy or observation [86]. The proportion of patients with failure-free survival (FFS; time from randomization to relapse, nonprotocol treatment, or death) at 3 years was significantly higher with R-CHOP than with CHOP (53\% vs $46 \%$; HR $0.78, P=0.04$ ). In addition, the 2-year FFS rate from the second randomization was $76 \%$ for rituximab maintenance therapy compared with $61 \%$ for observation $(P=0.009)$. Subanalyses showed that rituximab maintenance therapy significantly prolonged FFS after CHOP therapy (HR 0.45, $P=0.0004$ ) but not after RCHOP therapy, thus implying that rituximab maintenance therapy after rituximab-based immunochemotherapy does not provide additional clinical benefit in patients aged 60 years or older with DLBCL. No significant differences in OS were reported.

In terms of younger patients, the MabThera International Trial (MInT) Group confirmed the benefit of adding rituximab therapy to $\mathrm{CHOP}$ chemotherapy compared with $\mathrm{CHOP}$ chemotherapy alone (given for a total of six cycles) in patients aged 18-60 years with previously untreated, good-prognosis DLBCL $[87,88]$. R-CHOP therapy was associated with a significant increase in 3-year EFS rate (79\% vs $59 \% ; P<0.0001)$, 3 -year PFS rate $(85 \%$ vs $68 \%$; $P<0.0001)$, and 3 -year OS rate $(93 \%$ vs $84 \%$; $P=0.0001)$ compared with CHOP chemotherapy alone [87] (Table 3). In the R-CHOP and CHOP groups, patients considered to be at low risk (IPI score of 0 and no bulky disease) had significantly longer EFS than those at higher risk (IPI score of 1, bulky disease, or both). Importantly, subsequent follow-up reports from the GELA trial and MInT indicated that the beneficial effect of R-CHOP therapy over CHOP chemotherapy alone was sustained over the longer term in both older patients (GELA trial, 5 -year OS rate $58 \%$ vs $45 \%, P=0.007$; 10 -year OS rate $44 \%$ vs $28 \%, P<0.0001)[89,90]$ and younger patients (MInT, 6-year OS rate $90 \%$ vs $80 \%, P=0.0004$ ) [88]. Comparison of rituximab maintenance therapy and observation only in the randomized NHL-13 trial, which enrolled 683 patients with DLBCL who had responded to first-line rituximab therapy plus CHOP-like chemotherapy, showed no difference in the primary end point of EFS after a median follow-up of 45 months [91]; however, PFS was significantly improved in the maintenance therapy arm relative to the observation arm.

Salvage chemotherapy may be an option for patients with DLBCL that is refractory to induction therapy or who subsequently relapse after achieving a CR. As monotherapy, 


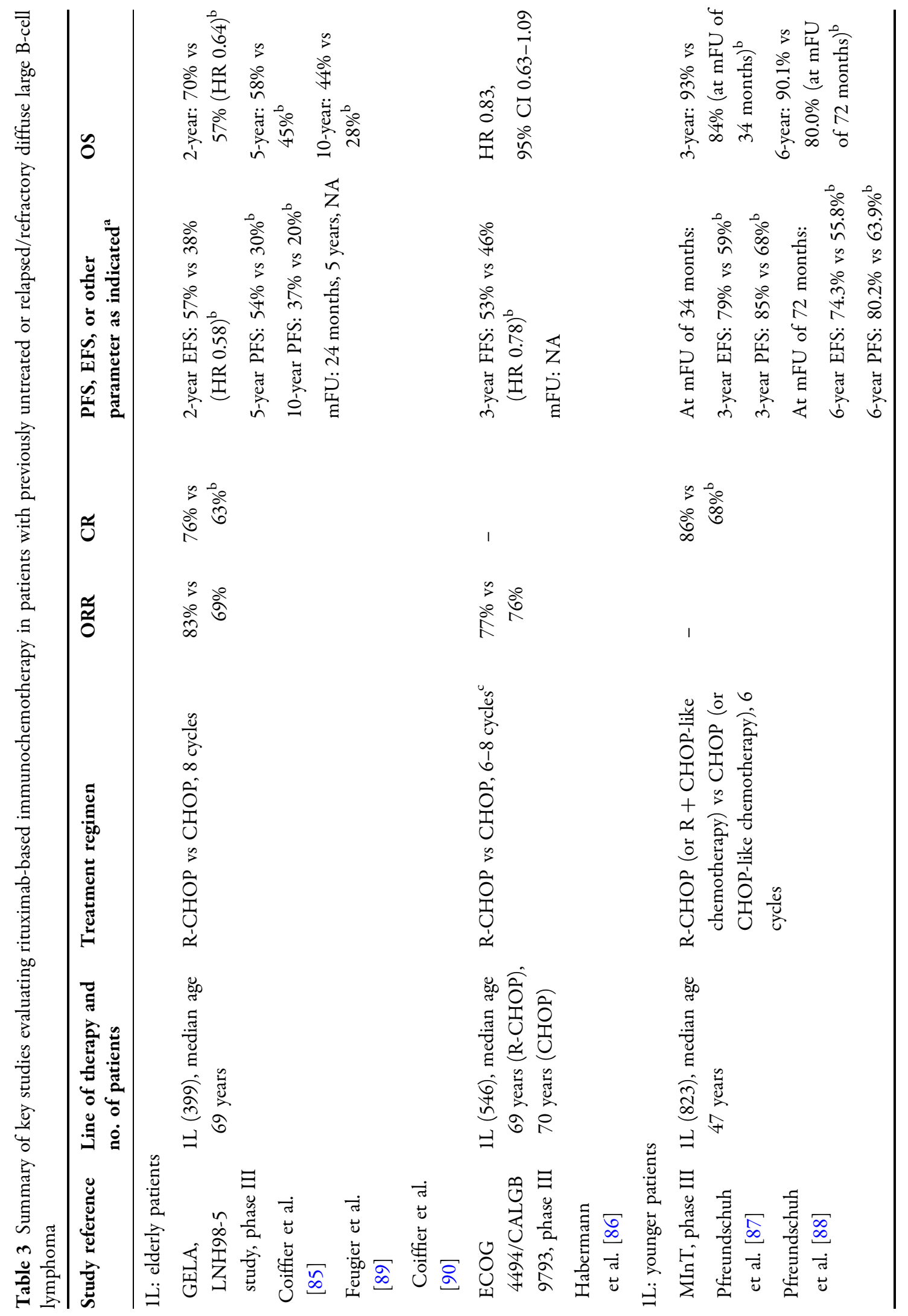




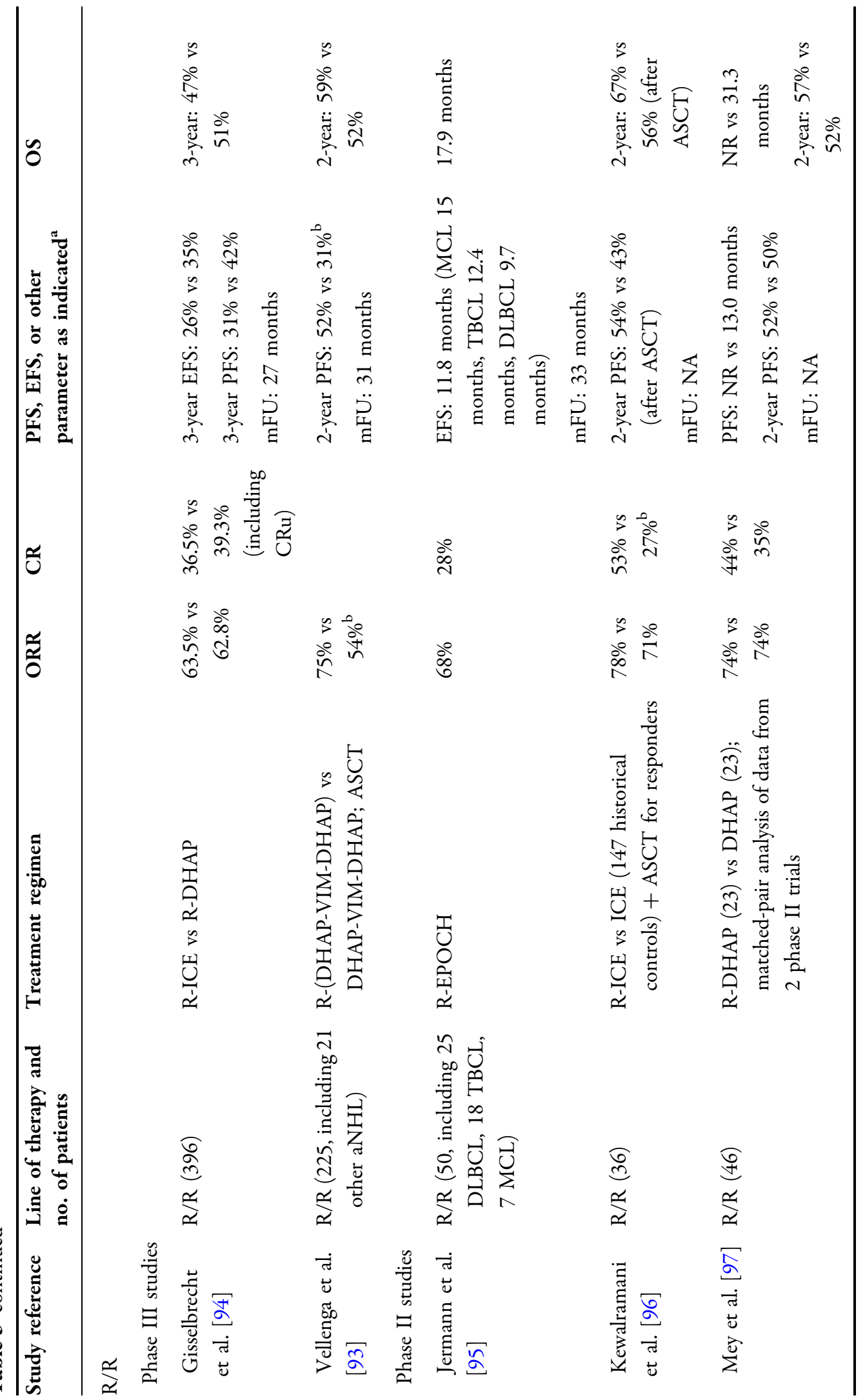




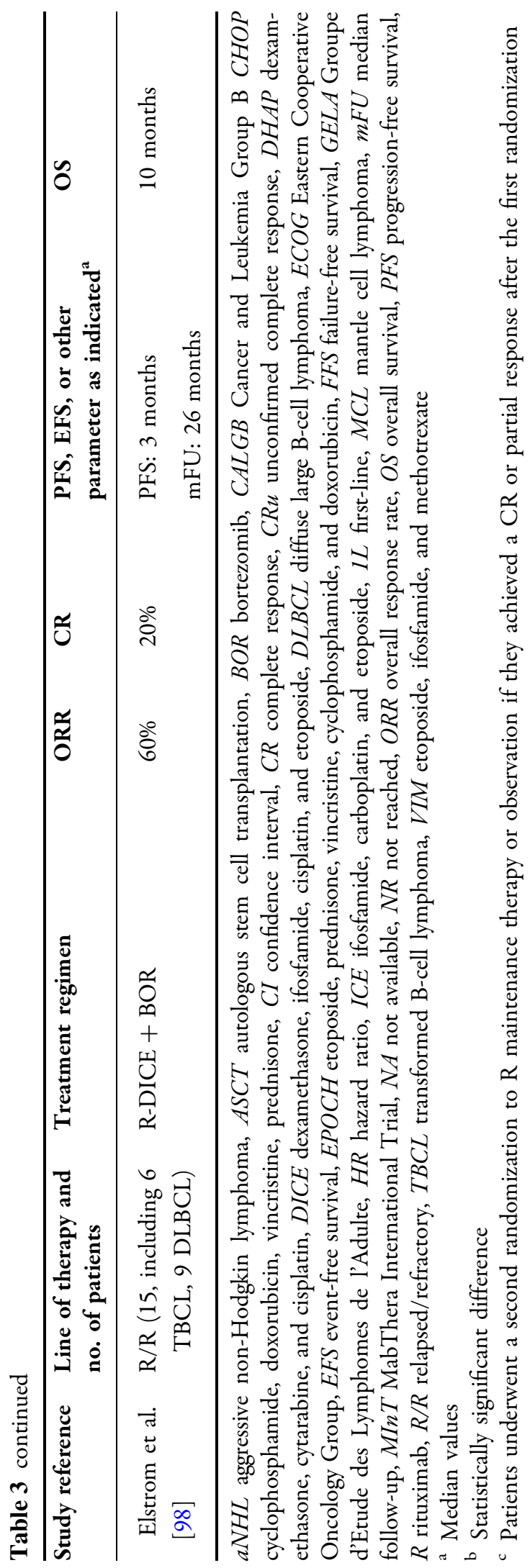

rituximab achieved promising response rates in 54 patients, mostly with relapsed/refractory DLBCL, in a phase II study [92]. Subsequently, rituximab was evaluated in combination with a variety of salvage chemotherapy regimens in phase II and phase III studies in this setting, including ifosfamide, carboplatin, and etoposide (ICE), dexamethasone, cytosine arabinoside, and cisplatin (DHAP), and etoposide, ifosfamide, and methotrexate (VIM) regimens (Table 3). In a randomized phase III study, the addition of rituximab therapy to DHAPVIM-DHAP therapy followed by autologous stem cell transplantation in 225 patients with relapsed or refractory aggressive NHL resulted in a significant improvement in FFS and PFS compared with chemotherapy alone [93]. The second randomized phase III trial, in 396 patients, demonstrated similar efficacy results for rituximab plus ICE and rituximab plus DHAP but did not include a chemotherapy-only arm; the study authors considered that neither regimen offered any benefit over other rituximab-based regimens given before or after autologous stem cell transplantation in previous studies [94]. Other studies in this setting were smaller in scale (50 or fewer patients) and did not include control arms [95-98]; however, the findings from two of these studies suggested potential benefits from the addition of rituximab therapy to chemotherapy when compared with historical data $[95,96]$ (Table 3).

\section{Rituximab in Chronic Lymphocytic Leukemia}

In Europe and the USA, intravenously administered rituximab is approved in combination with chemotherapy for the treatment of patients with previously untreated and relapsed/refractory CLL [11, 23, 29, 30]. Two large phase III randomized studies investigating the concurrent administration of rituximab plus FC (R-FC) compared with FC alone were conducted in patients with CLL $[99,100]$ (Table 4). Both studies were initiated on the basis of the findings of earlier phase I/II monotherapy and combination chemotherapy studies [101-106]. In the CLL8 trial, R-FC was compared with FC alone in patients with CLL 


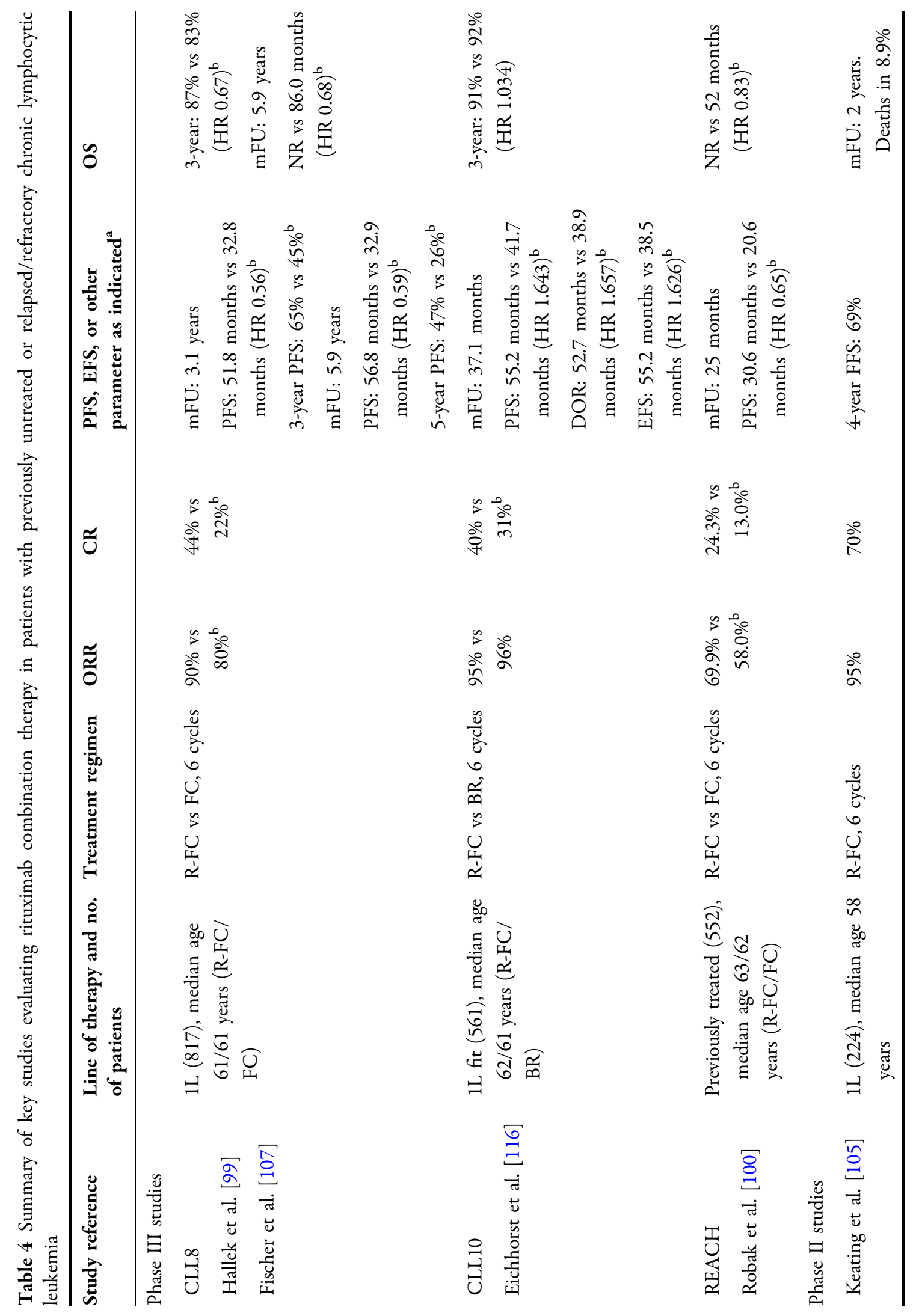




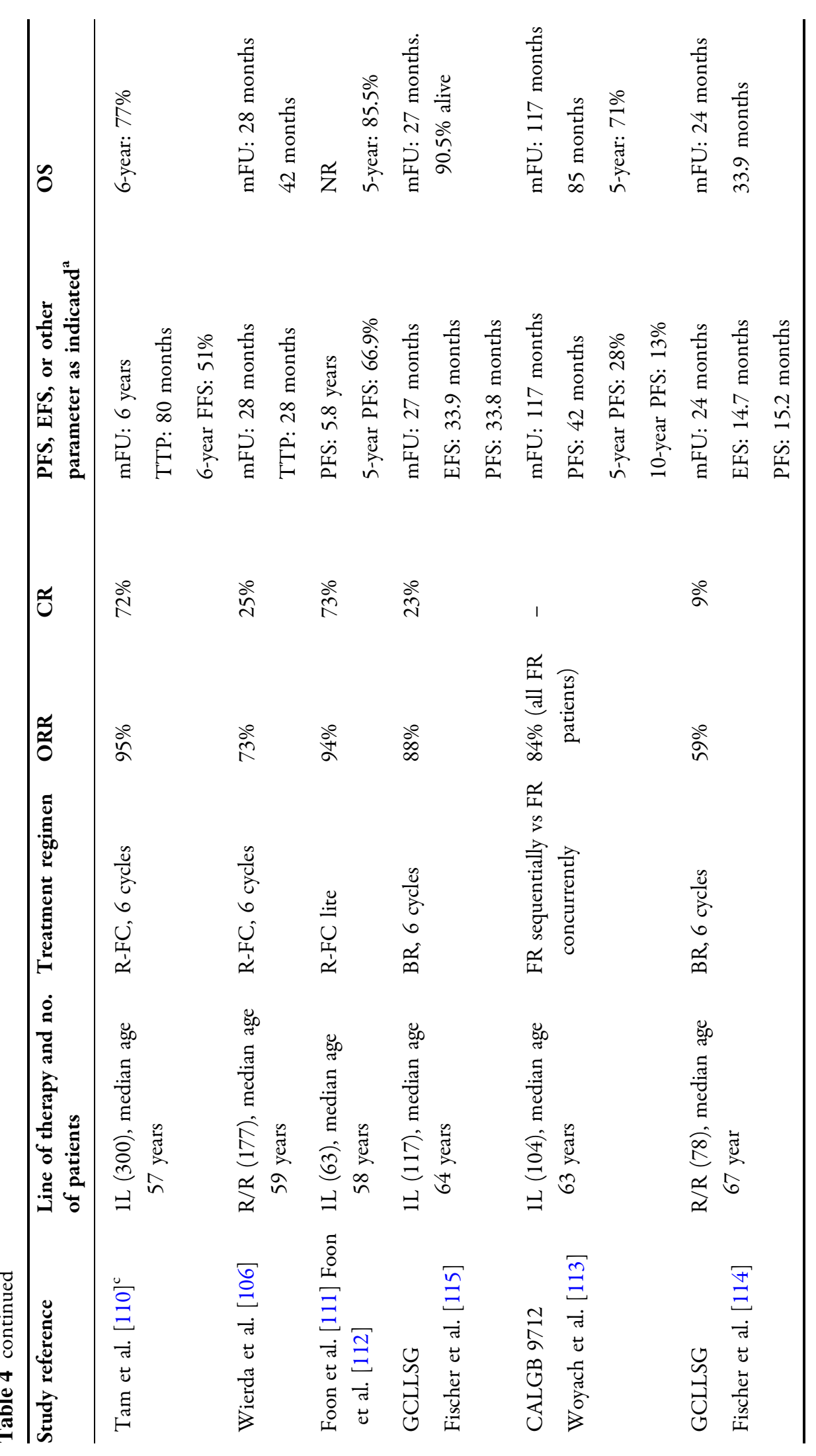




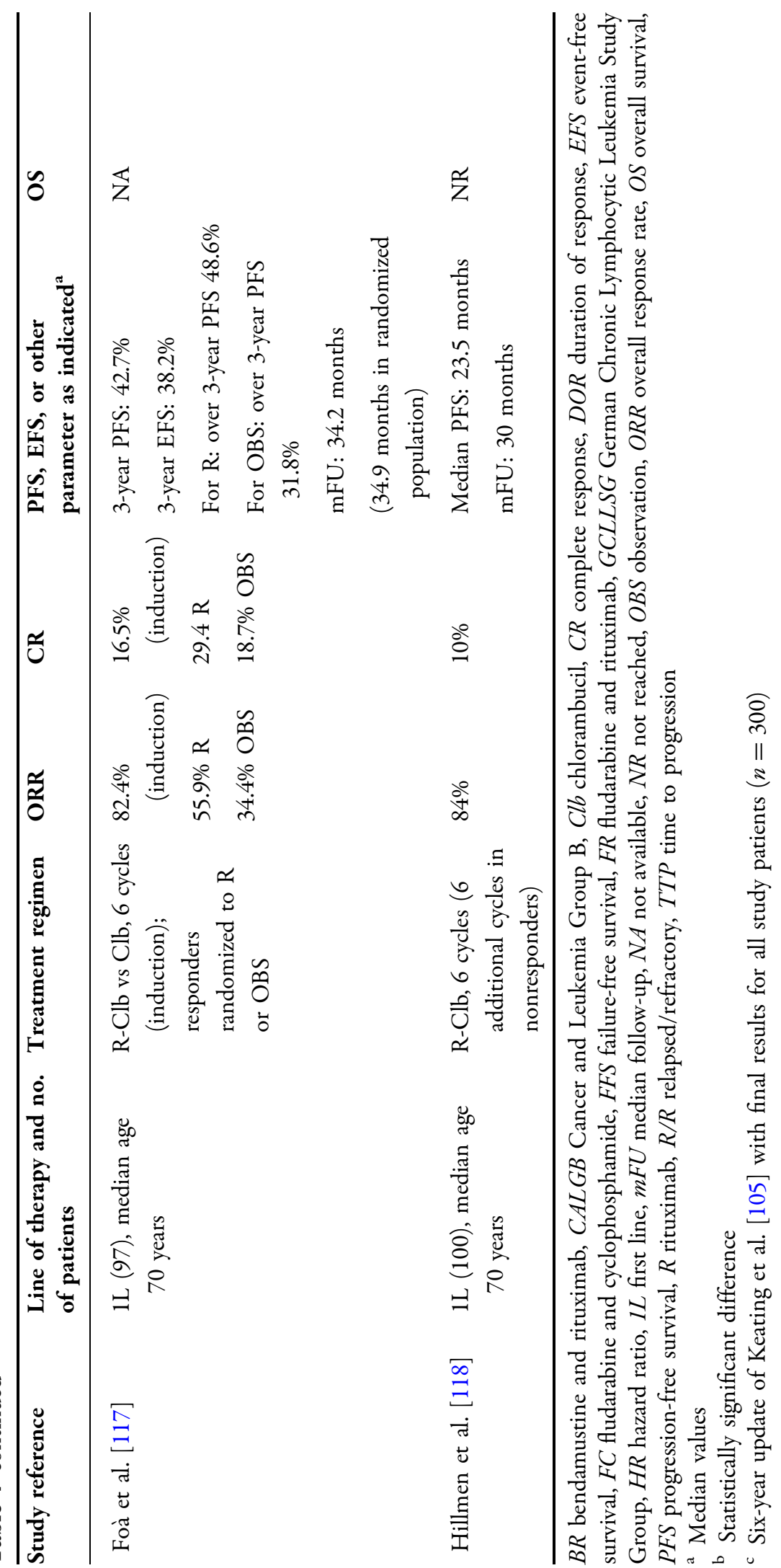


who had not received any prior chemotherapy [99]. Median PFS was significantly prolonged (by 19 months) with R-FC compared with FC (HR $0.56, P<0.0001)$, with results favoring R-FC for all three Binet stage subgroups. A significant benefit in favor of R-FC over FC was also observed in terms of OS (HR 0.67, $P=0.012$ ), and ORR and $C R$ rate $(P<0.0001)$ [99]. In an updated analysis of the CLL8 trial, median PFS with R-FC was almost twice as long as with FC (56.8 months vs 32.9 months; HR 0.59, $P<0.001)$ and median OS was also significantly prolonged (R-FC, not reached; FC, 86.0 months; HR 0.68, $P=0.001$ ) [107]. In previously treated patients with CLL in the REACH study, R-FC treatment was associated with a 10-month improvement in median PFS compared with FC (30.6 months vs 20.6 months; HR 0.65, $P<0.001)$ [100]. Consistent with the CLL8 study, improvements in PFS in the R-FC arm were also associated with significant increases in both the ORR and the CR rate. On the basis of the findings from these studies, R-FC became a first-choice treatment for patients with newly diagnosed or relapsed CD20 ${ }^{+}$CLL. Indeed, R-FC may be able to affect a cure in a subset of CLL patients with favorable genetic profiles: longterm follow-up of patients treated with R-FC in clinical trials has shown that those with mutated Ig heavy chain variable region gene status and without the $17 \mathrm{p}$ and $11 \mathrm{q}$ deletions achieve very long remissions [107-109].

Data from other, mostly phase II studies evaluating rituximab combination therapy in patients with previously untreated and relapsed/refractory CLL have also been published, and are summarized in Table 4 . These data are consistent with the results of the CLL8 and REACH studies, and provide further confirmation of the clinical efficacy of R-FC in CLL $[105,106,110-113]$. Promising results have also been reported with the combination of rituximab and bendamustine in a phase II study involving patients with both previously untreated and relapsed/refractory CLL [114, 115]. However, recently published data from the phase III CLL10 trial in 564 previously untreated, fit CLL patients showed that rituximab plus bendamustine was associated with significantly shorter PFS than R-FC (median
41.7 months vs 55.2 months; HR 1.64, $P=0.0003)$ [116]. Although there was a clear difference in PFS between the two study treatments in the overall patient population, subgroup analyses showed that the PFS benefit in the R-FC arm was significant only in younger patients (65 years or younger). Additionally, the tolerability (notably the incidence of severe infections) was better with rituximab plus bendamustine, particularly among patients older than 65 years. Taken together, these findings suggest that although R-FC may be the more effective regimen overall, rituximab plus bendamustine may have a role in the treatment of fit, older patients with CLL.

Another widely used treatment option for less fit patients with CLL is rituximab plus chlorambucil. In two phase II studies in previously untreated patients who received the combination ( $n=85$ and 100), adverse event (AE) profiles were favorable, and ORRs of up to $84 \%$ were achieved, with CR rates of $17 \%$ and $10 \%[117,118]$.

The potential benefit of rituximab maintenance therapy in CLL has also been explored in a small number of studies, with some encouraging results [119-121]. In a phase II study in previously untreated CLL patients, for example, 4-year PFS and OS rates were $74.8 \%$ and $93.7 \%$, respectively, in 67 patients who received rituximab maintenance therapy after responding to R-FCM induction therapy, compared with $69.1 \%$ and $90.5 \%$, respectively, for the patient population overall $(n=81$; treated with R-FCM as induction therapy with or without rituximab maintenance therapy) [120]. Results from the randomized CLL 2007 SA trial of 2 years of rituximab maintenance therapy versus observation following induction therapy with four cycles of R-FC therapy in patients aged 65 years or older included a significant improvement in median PFS (59.3 months vs 49.0 months; HR $0.60, P=0.001)$. Rituximab maintenance therapy also improved PFS in patients with genetic markers indicative of poorer prognosis, although no difference in 3-year OS was seen, and maintenance treatment was associated with a greater incidence of AEs [121]. In addition, studies are ongoing to determine the efficacy and safety of rituximab in combination with 
newer agents such as inhibitors of Bruton's tyrosine kinase and phosphoinositide 3-kinase, as well as inhibitors of the mechanistic target of rapamycin, and BCL2 inhibitors [122-125]. However, approval of these new drugs could be many years away in many countries, and in those with more limited healthcare budgets, the cost of these agents is likely to be prohibitive; for this reason, immunochemotherapy with rituximab combined with FC, bendamustine, or chlorambucil will continue to be a mainstay of patient treatment.

\section{Other B-Cell Malignancies}

Encouraging results have also been reported in four studies of rituximab in other B-cell malignancies for which use of the drug is not yet licensed.

In the final report of the randomized IELSG-19 study in 454 patients with extranodal marginal-zone B-cell lymphoma, a combination of rituximab and chlorambucil was associated with significantly longer EFS and PFS than chlorambucil or rituximab alone after a median follow-up of 7.4 years [126]. In a randomized phase III trial of 52 nonfollicular indolent NHL patients with low tumor burden who responded to rituximab induction therapy, those who received 3-monthly rituximab maintenance therapy had a 3.5-fold longer time to treatment failure than those who received retreatment at the time of progression [127]. In two other trials that assessed the addition of rituximab therapy to chemotherapy in highly aggressive lymphoid malignancies, significant increases in EFS relative to chemotherapy alone were seen in 209 patients with $\mathrm{CD}_{20}^{+}$, Philadelphia chromosome-negative acute lymphoblastic leukemia after a median follow-up of 30 months [128], and in 260 patients with previously untreated Burkitt lymphoma after a median follow-up of 38 months [129].

Rituximab has also been shown to improve OS in older patients with MCL, both in the first-line setting when added to induction chemotherapy and when used as maintenance therapy after rituximab therapy plus chemotherapy as induction therapy [130, 131].
Additional B-cell malignancies in which rituximab treatment has been associated with positive outcomes in phase II and phase III clinical trials include Waldenström macroglobulinemia, posttransplant lymphoproliferative disorders, and Hodgkin lymphoma [132-134]. Rituximab is not yet licensed for use in any of these diseases.

\section{Development of Resistance to Rituximab}

Although the efficacy of rituximab for the treatment of B-cell hematologic malignancies is well established, some patients do not respond to first-line treatment, and others experience relapse after initial response to therapy $[54,135]$.

Despite many years of study, the exact mechanisms underlying the development of resistance to rituximab remain unclear. However, given the reliance of rituximab on immune-effector mechanisms for its antitumor efficacy, it has been hypothesized that intrinsic tumor cell alterations and the host immunologic environment may both play a role. There are many postulated in vivo mechanisms of resistance, and these are described in detail elsewhere [136, 137]. In brief, they include inhibition of three of the pathways that are involved in the mechanism of action of rituximab; namely, CDC, ADCC, and apoptosis. Complement depletion, through exhaustion of the store of complement proteins, has been implicated in the development of resistance to rituximab-mediated CDC. Furthermore, host immunologic factors, such as polymorphism of Fc $\gamma$ receptor IIIa on cytotoxic cells, may affect the sensitivity of tumor cells to ADCC, whereas alterations in apoptotic pathway signaling, through overexpression of antiapoptotic gene products, may facilitate the development of apoptosis resistance in the presence of rituximab [136, 137]. Another possible mechanism of rituximab resistance is loss of the CD20 target antigen, which has been demonstrated in lymphoma cell lines and in biopsy samples from relapsed patients $[138,139]$. This phenomenon may occur in several ways, including decreased expression at both the pretranslational level 
and the posttranslational level, antigenic modulation (whereby CD20 antibody-antigen complexes are internalized following rituximab binding), or the acquisition of CD20 mutations. Removal of rituximab/CD20 complexes from the B-cell surface by monocytes in a process called "trogocytosis" or "CD20 shaving" has also been reported [140]. In addition, generation of rituximab-resistant clones, the tumor microenvironment, and the PK profile of rituximab may also have a role in the development of rituximab resistance [136, 137].

Patients treated with rituximab may develop an antibody against rituximab, termed "human antichimeric antibody." These patients have the potential to mount allergic reactions when subsequently treated with other antibodies. To date, immune responses against rituximab have been much more common in patients treated for rheumatoid arthritis than in those with other diseases. During clinical trials in patients with B-cell malignancies, up to $2 \%$ of patients developed human antichimeric antibody, but no effect of this antibody on the efficacy or safety of rituximab has been demonstrated $[29,30]$.

Various strategies are being investigated to overcome rituximab resistance. One such approach is the use of adjuncts to inhibit hyperactivated survival/antiapoptotic pathways, which regulate downstream antiapoptotic gene products. Possible candidates include histone deacetylase inhibitors, targeted chemical inhibitors, proteasome inhibitors, selective inhibitors for antiapoptotic gene products, and microRNAs [137]. The combination of rituximab and lenalidomide, an immunomodulatory drug that has been shown to enhance ADCC in in vitro and in vivo leukemia models, has demonstrated efficacy in patients with indolent B-cell lymphomas, DLBCL, and CLL who were rituximab resistant or had previously relapsed following rituximab therapy [141-144]. Another important avenue of research to counter rituximab resistance is the development of novel, next-generation anti-CD20 $m A b s$ with different mechanisms of action. This approach is exemplified by obinutuzumab, a second-generation type II anti-CD20 mAb, which has recently been approved in combination with bendamustine followed by single-agent maintenance therapy for the treatment of patients with FL who do not respond to or whose disease progresses after treatment with rituximab or a rituximab-containing regimen [145].

\section{SAFETY AND TOLERABILITY OF RITUXIMAB IN PATIENTS WITH HEMATOLOGIC MALIGNANCIES}

\section{Overview of the Safety Profile}

With 20 years of postmarketing surveillance experience and more than four million patient exposures, the safety profile of rituximab, both as monotherapy (induction and/or maintenance) and in combination with chemotherapy, in the treatment of patients with B-cell hematologic malignancies is very well defined. Furthermore, in the two decades since the regulatory approval of rituximab, no new or unexpected safety signals have been identified, thus confirming a favorable therapeutic window.

From clinical trial and postmarketing surveillance data from patients with NHL and CLL, infusion-related reactions (IRRs) were identified as the most common adverse drug reactions (ADRs) in patients treated with rituximab as monotherapy or combination therapy $[29,30]$. In those studies, IRRs of any grade and type, including cytokine-release syndrome, were observed in $77 \%$ of patients. Severe IRRs (grade 3 or 4), including bronchospasm and hypotension, were reported in $12 \%$ of patients [29]. Although rare, fatal reactions have occurred within $24 \mathrm{~h}$ of drug infusion (most commonly with the first infusion), and it is therefore recommended that patients be closely monitored, and treatment be stopped if there is a severe reaction [30]. Most IRRs occurred during the first rituximab infusion (in the first 1-2 $\mathrm{h}$ ), and the frequency of reactions typically decreased with subsequent infusions, to less than $1 \%$ after eight doses of rituximab $[29,30]$. Now that physicians have more experience of 
rituximab administration, the management of IRRs has improved, for example, by use of slower infusion rates and by premedication (described later), and IRRs now occur less frequently than during the registration trials.

In addition to IRRs, other common AEs reported in patients treated with rituximab include infections, hematologic AEs, and cardiovascular events. Infections (bacterial and viral) were reported in approximately $30-55 \%$ of patients with NHL and in about $30-50 \%$ of patients with CLL in clinical trials. Grade 3/4 infections occurred in approximately $4 \%$ of patients treated with rituximab as monotherapy in randomized studies, and were more common with rituximab maintenance therapy than with observation [29, 30]. Documented infections in rituximab-treated patients included localized Candida infections, herpes zoster, and cytomegalovirus infections. Rarely, cases of fatal progressive multifocal leukoencephalopathy and severe mucocutaneous reactions, some of which were fatal, have occurred [30]. Hepatitis B reactivation has also been reported, mainly in patients receiving rituximab plus chemotherapy, with outcomes of fulminant hepatitis, hepatic failure, and death in some cases [30]. Among patients with relapsed/refractory CLL, grade $3 / 4$ hepatitis $B$ (reactivation and primary infection) was reported in $2 \%$ of patients treated with R-FC compared with $0 \%$ of patients treated with FC [29].

Generally mild and reversible cytopenias, including neutropenia, leukopenia, and thrombocytopenia, were reported during treatment with rituximab as monotherapy for 4 weeks in clinical trials, and grade $3 / 4$ events were relatively uncommon, occurring in $4.2 \%$ (neutropenia), $1.1 \%$ (anemia), and $1.7 \%$ (thrombocytopenia) of patients [29]. Compared with observation, patients treated with rituximab as maintenance therapy for up to 2 years experienced a higher incidence of grade $3 / 4$ leukopenia (5\% vs $2 \%$ ) and neutropenia (10\% vs $4 \%)$ but a similar low incidence of thrombocytopenia (both less than 1\%). In clinical studies in NHL and CLL, rituximab therapy plus chemotherapy (CHOP, FC, or CVP) was generally associated with a higher incidence of grade 3/4 leukopenia, neutropenia, and pancytopenia compared with chemotherapy alone [29, 30]; however, despite the increased incidence of neutropenia, patients treated with rituximab plus chemotherapy were not at higher risk of developing infections compared with patients treated with chemotherapy alone [29]. In studies in previously untreated and relapsed/refractory CLL, prolonged neutropenia (resolving between 24 and 42 days after the last dose) or late-onset neutropenia (resolving later than 42 days after the last dose) was reported more frequently in those receiving R-FC than in those receiving FC alone (up to $25 \%$ of R-FC patients) $[29,30]$.

Cardiovascular events were reported in up to $25 \%$ of patients receiving rituximab monotherapy in clinical trials, most commonly hypotension and hypertension $[29,30]$. Some cases of grade $3 / 4$ arrhythmias and angina pectoris were also reported during infusion of rituximab. In the maintenance setting, cardiac disorders were reported as serious AEs in 3\% of rituximab-treated patients and in less than $1 \%$ of untreated patients [29]. In studies evaluating rituximab in combination with chemotherapy, $\mathrm{R}-\mathrm{CHOP}$ was associated with a higher incidence of grade $3 / 4$ cardiac arrhythmias (mainly tachycardia and atrial flutter/fibrillation) compared with CHOP $[29,30]$; however, there was no difference between R-CHOP and CHOP in terms of the incidence of other grade $3 / 4$ cardiac events, including heart failure, myocardial disease, and manifestations of coronary artery disease [29].

Other common AEs reported with rituximab therapy include respiratory system disorders (e.g., dyspnea, cough, and chest pain), gastrointestinal disorders (e.g., nausea, vomiting, and diarrhea), skin and suncutaneous tissue disorders (e.g., pruritus, rash, and urticaria), metabolic disorders (e.g., angioedema and hyperglycemia), and nervous system disorders (e.g., paresthesia, hypoesthesia, and agitation) $[29,30]$. In addition, IgG levels are frequently reduced among rituximab-treated patients, with levels below the lower limit of normal reported in approximately $60 \%$ of patients with FL receiving rituximab maintenance therapy for 2 years (vs 36\% in the observation group) [29]. 


\section{Safety in Patient Subpopulations}

In the current summary of product characteristics for rituximab, brief reference is made to the tolerability profile of rituximab monotherapy in specific patient subpopulations with NHL, including older patients (65 years or older), patients with bulky disease, and patients undergoing retreatment [29]. In older patients, the incidence of ADRs (all grades) and grade 3/4 ADRs is generally similar to that seen in younger patients (younger than 65 years). However, in patients with previously untreated or relapsed/refractory CLL treated with rituximab plus chemotherapy, the incidence and severity of grade 3/4 hematologic AEs and bacterial infections was found to be higher in patients aged 70 years or older than in younger patients [30]. In the monotherapy setting, patients with bulky B-cell lymphomas experienced a higher incidence of grade 3/4 ADRs than those with nonbulky disease $(25.6 \%$ vs $15.4 \%)$, although the incidence of ADRs of any grade was generally similar in the two groups [29]. Retreating patients with further courses of rituximab monotherapy does not appear to affect the drug's tolerability profile, with the proportion of patients experiencing ADRs during later treatment courses being similar to that during initial exposure (both for grade 3/4 ADRs and for ADRs of any grade) [29]. Information on the safety profile of rituximab in children and adolescents is currently scarce, but a randomized phase III trial that is assessing the addition of rituximab therapy to chemotherapy in this subpopulation [146] will help to address this issue.

\section{Management and Prevention Strategies for Rituximab-Associated Adverse Events}

Current rituximab patient information provides details of management and prevention strategies for rituximab-associated AEs [29, 30]. Before infusion of rituximab, all patients should receive premedication, comprising an antihistamine and acetaminophen (paracetamol), to minimize the occurrence of cytokine-mediated reactions (flushing, low blood pressure, etc.). In patients with CLL, adequate hydration and administration of uricostatics starting $48 \mathrm{~h}$ before infusion of rituximab is recommended to reduce the risk of tumor lysis syndrome. Prednisone (100 mg intravenously) should also be administered shortly before rituximab infusion to decrease the rate and severity of acute infusion reactions and/or cytokine-release syndrome; European prescribing information recommends this for CLL patients with lymphocyte counts greater than $25 \times 10^{9} / \mathrm{L}$ [29] .

In the event of mild-to-moderate IRRs, the infusion rate should be decreased and then increased on symptom abatement. Some physicians use a more rapid infusion (90-min duration) for all infusions after the first dose, and this dosing option is approved in the USA. All patients should undergo screening for hepatitis B, including assessment of hepatitis B surface antigen and hepatitis B core antibody status, before treatment with rituximab because of the possible risk of reactivation of the disease. Consideration should also be given to withholding antihypertensive medicines $12 \mathrm{~h}$ before rituximab infusion because of the risk of hypotension.

\section{PHARMACOECONOMIC CONSIDERATIONS}

Numerous pharmacoeconomic analyses of rituximab have been conducted in the last 20 years that show rituximab is a cost-effective option compared with reference interventions for the treatment of B-cell hematologic malignancies, with the incremental cost-effectiveness ratios consistently at or below national willingness-to-pay thresholds. Table 5 presents a summary of the key findings from analyses published between 2010 and 2016, specifically evaluating the cost-effectiveness of intravenously administered rituximab for the treatment of FL [147-154], DLBCL [155-157], and CLL [158-161]. These studies were performed in a variety of countries (including several European countries, the USA, Canada, and Australia) from either a payer perspective or a societal perspective. Most of the analyses used Markov models that incorporated outcomes data from 


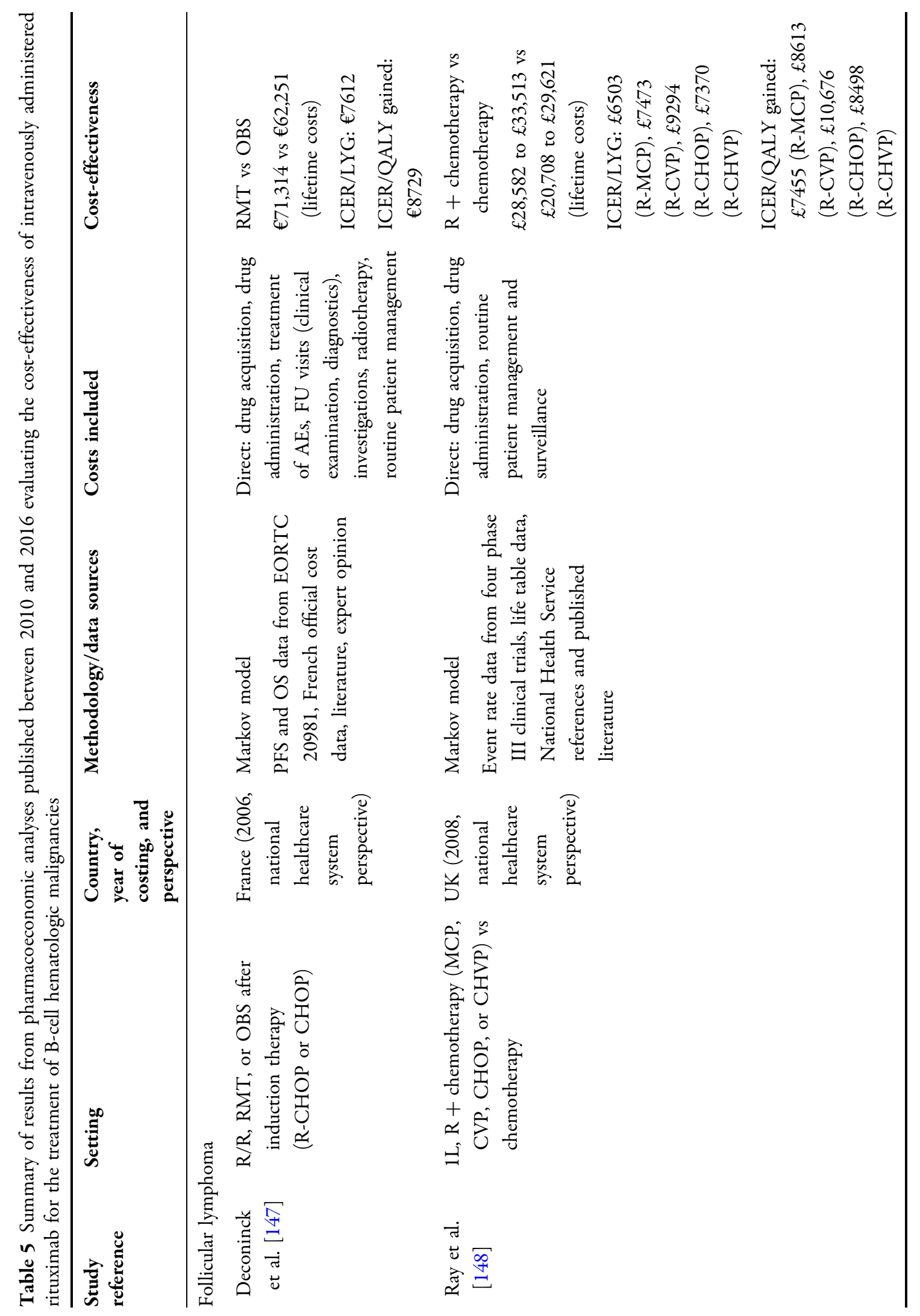




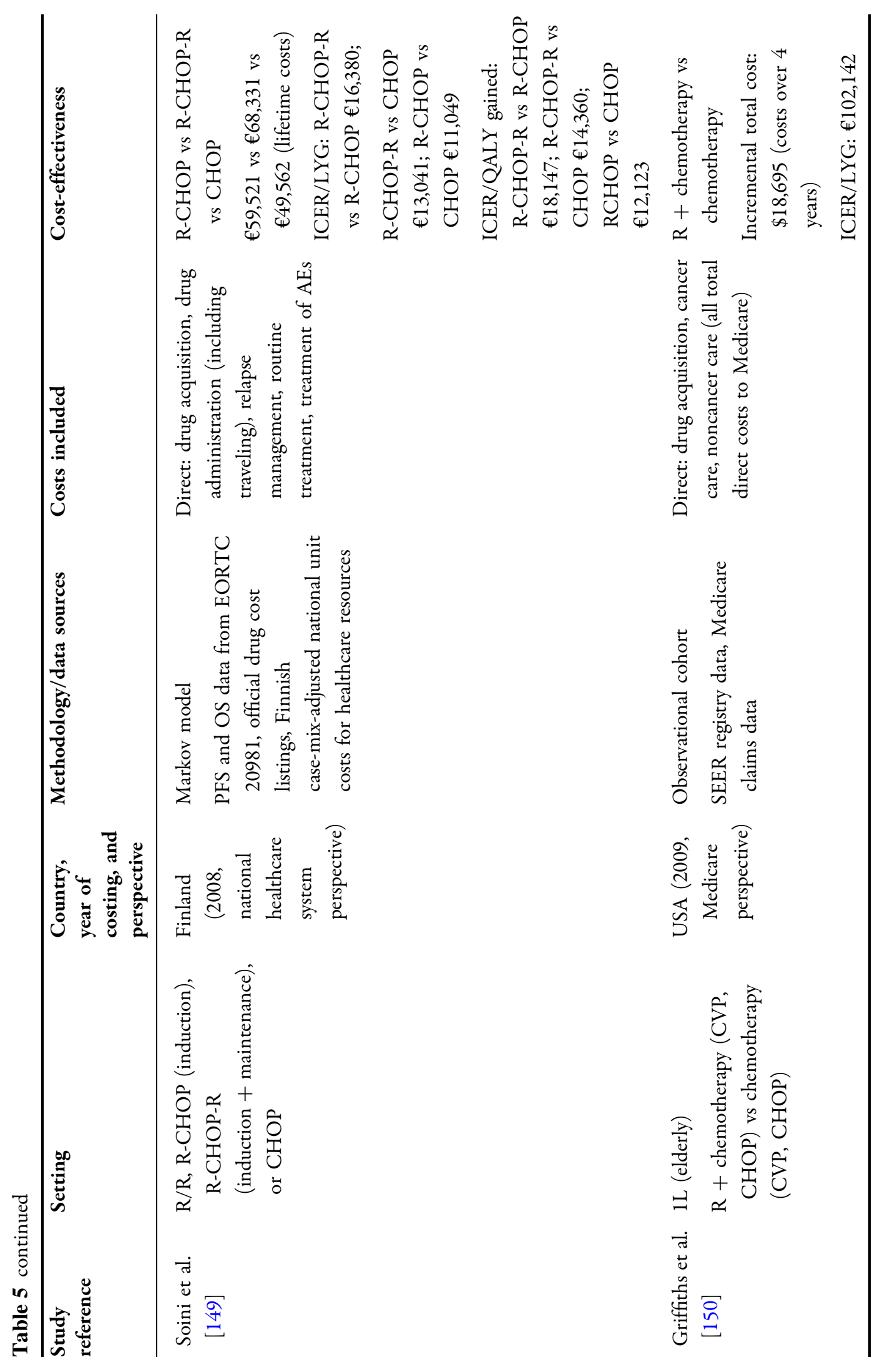




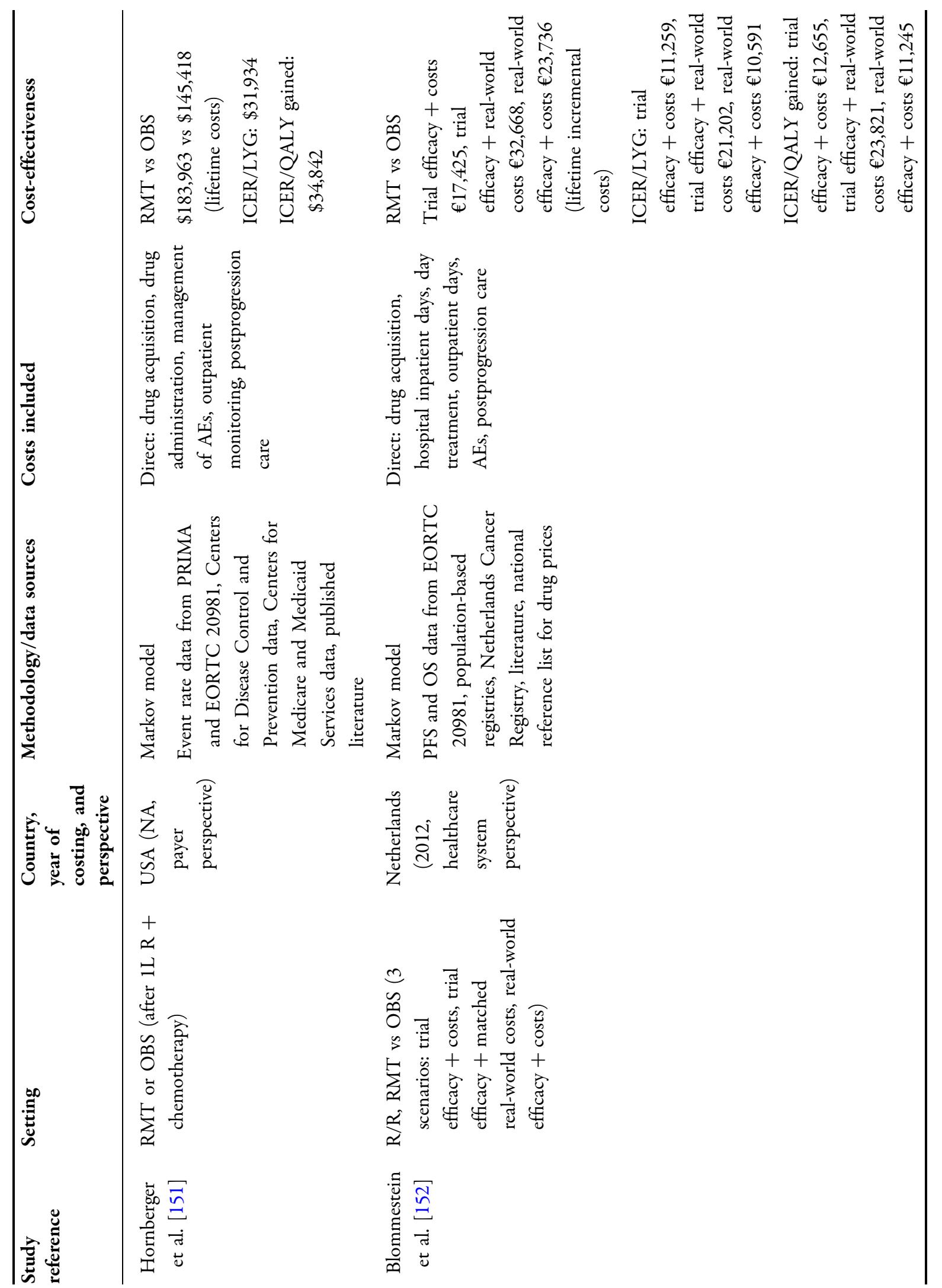




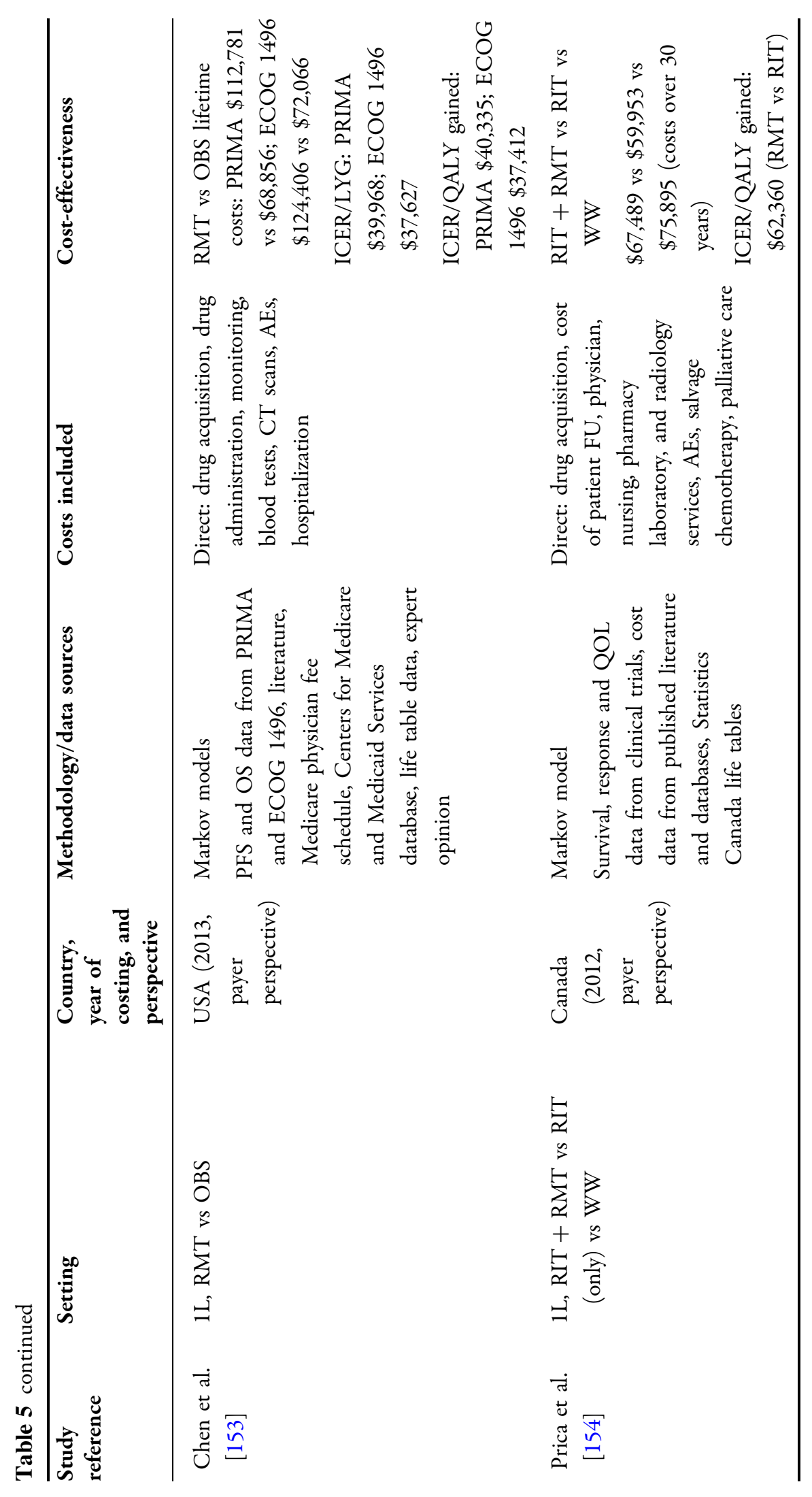




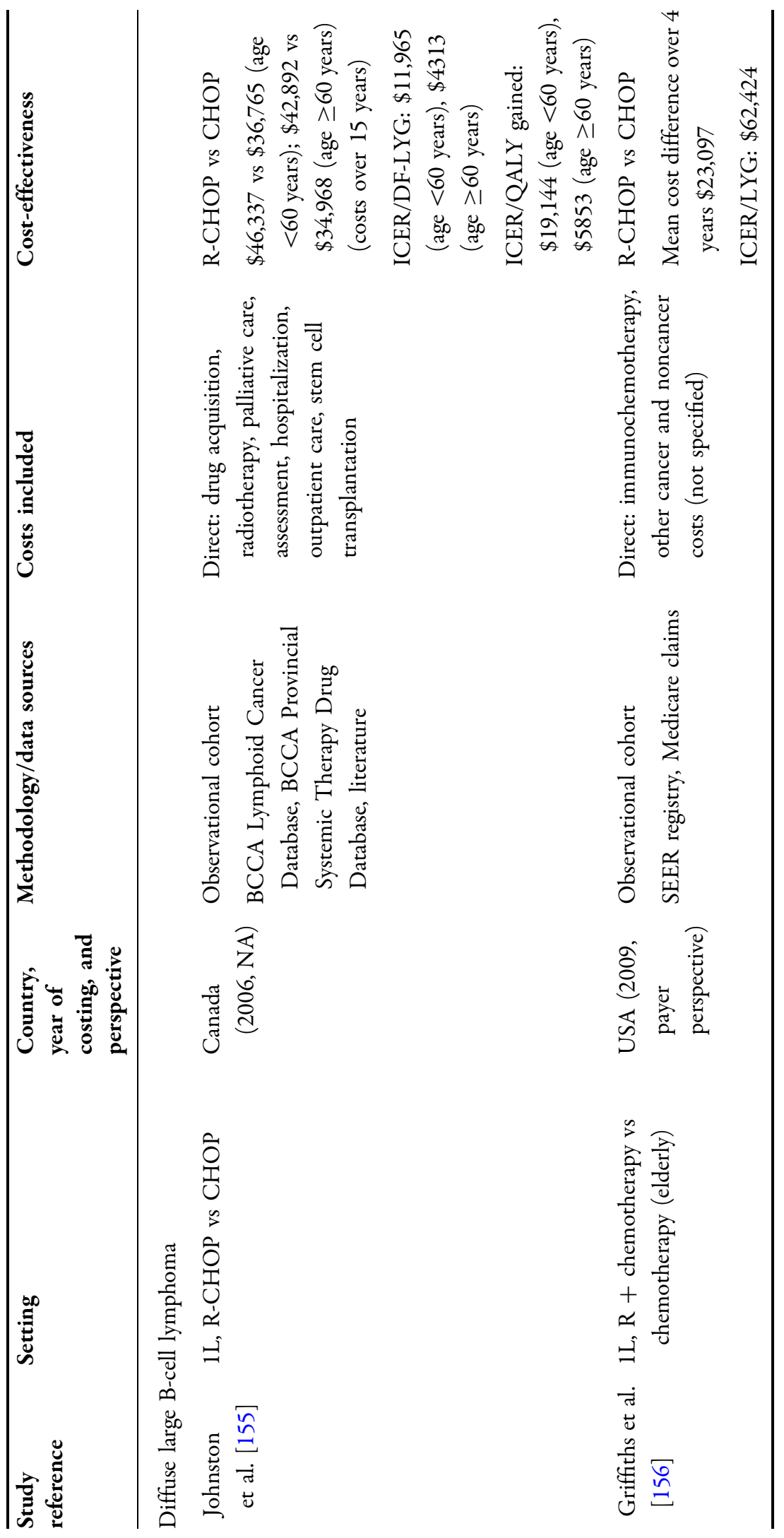




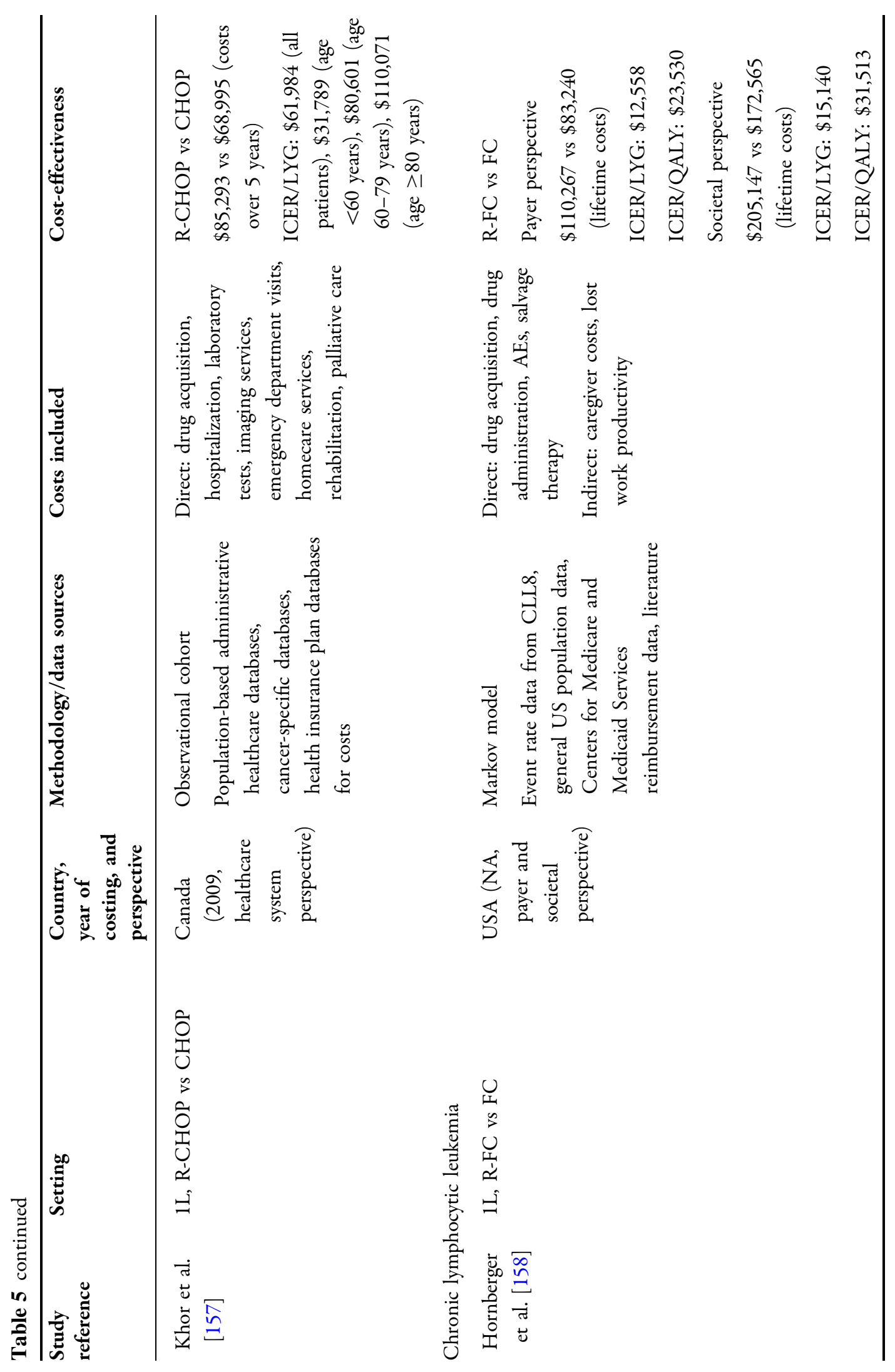




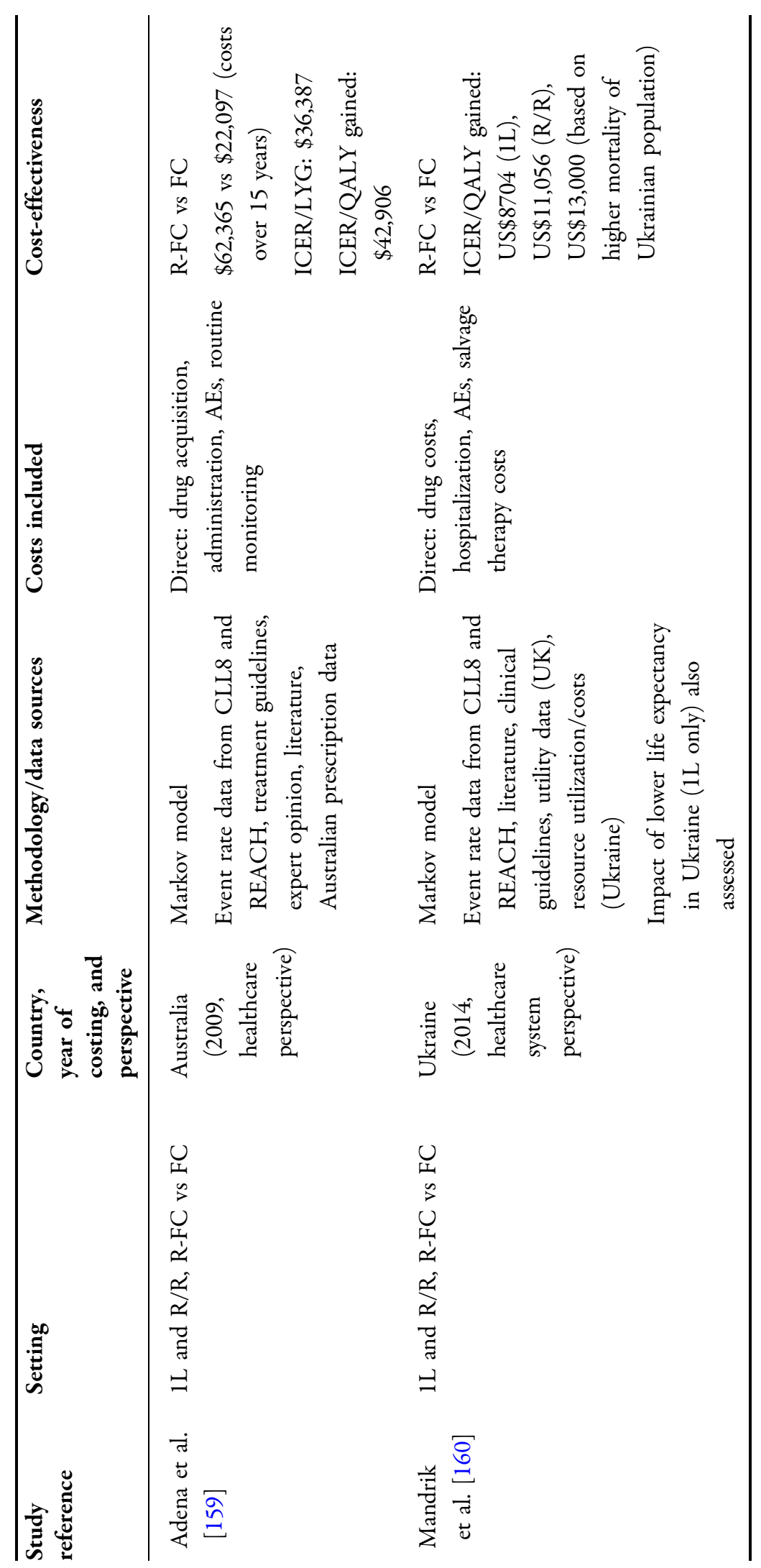




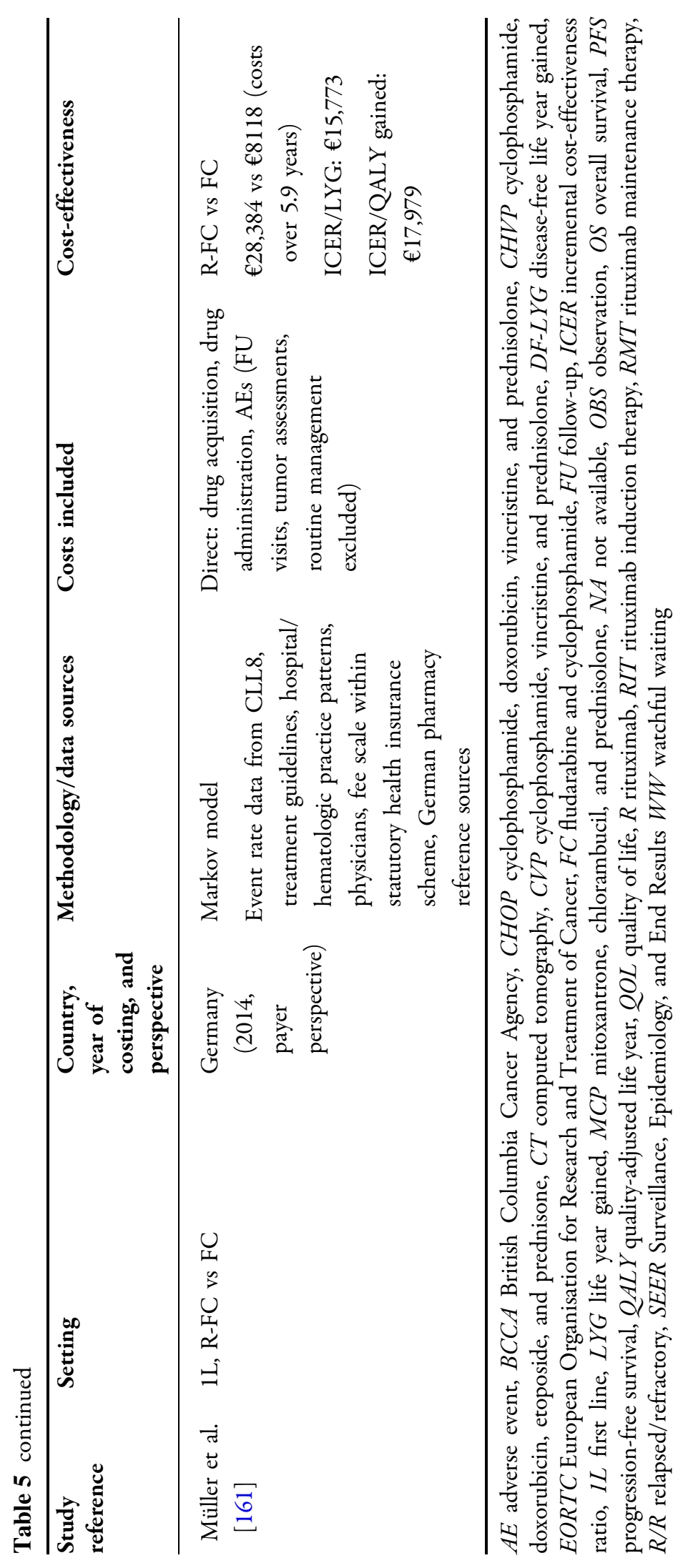


clinical trials, and a small number were based on real-life data from large observational cohorts.

In FL, rituximab was shown to be cost-effective both as maintenance therapy compared with observation in the first-line $[151,153]$ and relapsed/refractory $[147,149,152]$ settings and as induction therapy combined with chemotherapy compared with chemotherapy alone in previously untreated patients $[148,150]$. In DLBCL, rituximab therapy plus chemotherapy was generally found to be cost-effective compared with chemotherapy alone when administered as first-line treatment $[155,157]$, although results were conflicting as to whether cost-effectiveness increased or decreased with increasing age $[155,157]$. In one analysis based on data from a large observational cohort of DLBCL patients in the USA, previously reported cost savings associated with rituximab-related survival benefits in clinical trials were not realized; according to the study authors, this finding was consistent with an ongoing accrual of medical costs associated with multiple comorbidities among elderly cancer survivors treated with rituximab [156]. Cost-effectiveness analyses of rituximab in CLL evaluated rituximab therapy plus chemotherapy versus chemotherapy alone in patients with previously untreated and relapsed/refractory disease [158-161]. In both settings, rituximab therapy plus chemotherapy was considered cost-effective, although in the Ukraine this was considered applicable only under conditions of economic stability, cost-effectiveness threshold growth, or with rituximab price negotiations [160]. In an analysis that evaluated the economic benefit of adding rituximab therapy to FC chemotherapy in CLL in the USA, R-FC was found to be cost-effective from both a payer and a societal perspective [158].

A population analysis of the benefits and costs of rituximab in patients with FL, DLBCL, and CLL in the USA over a 15 -year period based on cancer registry data found that almost 280,000 cumulative life years were saved by combining rituximab therapy with chemotherapy, corresponding to a net economic gain of $\$ 16.5$ billion, when treatment costs were taken into account [162].

\section{CONCLUSION}

Since its first approval 20 years ago, the anti-CD20 mAb rituximab has changed the treatment landscape for patients with B-cell hematologic malignancies and established a new standard of care. By prolonging survival in a range of these diseases, rituximab has reduced mortality and improved the clinical prognosis for many patients with B-cell malignancies. Extensive clinical data from the last two decades have confirmed the efficacy of rituximab and allowed its tolerability profile to be clearly defined. On the basis of this evidence, rituximab is now incorporated routinely into treatment regimens for FL, DLBCL, CLL, and MCL: it is designated as a recommended treatment in current clinical practice guidelines for B-cell hematologic malignancies developed by the European Society of Medical Oncology and the US National Comprehensive Cancer Network $[9-11,22,23]$, and is included in the WHO Model List of Essential Medicines [24]. The experience with rituximab has confirmed the value of the $\mathrm{CD} 20$ protein as an important mechanistic target in the search for new lymphoma treatments. Advances in the design of anti-CD20 antibodies have resulted in the development of new therapies for the treatment of B-cell hematologic malignancies, such as obinutuzumab, which has shown benefit for the treatment of $\mathrm{FL}$, both as first-line treatment and in patients with rituximab-refractory disease, and CLL (see the reviews by Tobinai et al. [163] and Goede et al. [164] for detailed assessments of this agent). Other examples of newer agents include ofatumumab, veltuzumab, and ocrelizumab [165]. Both obinutuzumab and rituximab are important backbones of therapy in this setting for the foreseeable future. Another example of development of a drug that exploits the CD20 pathway is CD20/CD3 antibodies. Furthermore, the introduction of subcutaneously administered rituximab (extensively reviewed by Davies et al. [31]), with its simplified administration schedule, reduced treatment burden for patients, and the potential resource savings for healthcare systems, is likely to further strengthen the position of rituximab 
as an essential treatment for symptomatic, advanced B-cell malignancies.

\section{ACKNOWLEDGEMENTS}

The study and article processing charges, including the open access fee, were funded by F. Hoffmann-La Roche Ltd., Basel, Switzerland. Support for third-party writing assistance for the manuscript, provided by Cheryl Wright of Gardiner-Caldwell Communications, was funded by F. Hoffmann-La Roche Ltd., Basel, Switzerland. All authors had full access to the information included in this review and take complete responsibility for the integrity of the data discussions. All named authors meet the International Committee of Medical Journal Editors criteria for authorship for this article, take responsibility for the integrity of the work as a whole, and have given final approval for the version to be published. We thank all current and former researchers and investigators as well as patients and their families who participated in clinical trials establishing MabThera/Rituxan as an essential drug to treat patients with B-cell malignancies. We also thank Peter Morcos of Roche for his careful review and contributions to the pharmacokinetics section.

Compliance with Ethics Guidelines The information reported in this review is derived from previously conducted studies: this does not include any new studies of human or animal subjects performed by any of the authors. All authors had full access to the information included in this review and take complete responsibility for the integrity of the data discussions.

Disclosures Martin Barrett is an employee of Roche Products Ltd. and holds share options. Robin Foà has received honoraria from F. Hoffmann-La Roche Ltd. Joerg Maurer is an employee of F. Hoffmann-La Roche Ltd. and holds share options. Michael Wenger is an employee of F. Hoffmann-La Roche Ltd. and holds share options. David G. Maloney has nothing to disclose. Nancy Valente is an employee of Genentech Inc. and holds share options. Gilles Salles has received research and travel grant support and honoraria from $\mathrm{F}$. Hoffmann-la Roche Ltd., and honoraria from Amgen, BMS, Celgene, Gilead, Janssen, Kite, Merck, Morphosys, Novartis, and Servier. Susan O'Brien has received research grant support from ProNAI, Regeneron, and Acerta, and consultant/research support from Gilead, Pharmacyclics, TG Therapeutics, and Pfizer, and has acted as a consultant for Amgen, Astellas, Celgene, GlaxoSmithKline, Janssen Oncology, Aptose Biosciences Inc., Vaniam Group LLC, Abbvie, Sunesis, and Alexion.

Data availability Data sharing is not applicable to this article as no datasets were generated or analyzed during the current study.

Open Access. This article is distributed under the terms of the Creative Commons Attribution-NonCommercial 4.0 International License (http://creativecommons.org/licenses/by-nc/4.

$0 /$ ), which permits any noncommercial use, distribution, and reproduction in any medium, provided you give appropriate credit to the original author(s) and the source, provide a link to the Creative Commons license, and indicate if changes were made.

\section{REFERENCES}

1. Boffetta P. Epidemiology of adult non-Hodgkin lymphoma. Ann Oncol. 2011;22(Suppl 4):iv27-31.

2. Hallek M. Chronic lymphocytic leukemia: 2015 Update on diagnosis, risk stratification, and treatment. Am J Hematol. 2015;90:447-60.

3. National Cancer Institute. SEER cancer statistics review 1975-2013. Non-Hodgkin lymphoma. 2016. https://seer.cancer.gov/csr/1975_2013/results_merged/ sect_19_nhl.pdf. Accessed 21 Jun 2017.

4. Torre LA, Bray F, Siegel RL, et al. Global cancer statistics, 2012. CA Cancer J Clin. 2015;65:87-108.

5. Fisher SG, Fisher RI. The epidemiology of nonHodgkin's lymphoma. Oncogene. 2004;23:6524-34.

6. Cancer Research UK. Non-Hodgkin lymphoma (C82-C86): 1979-2013 European age-standardised incidence rates per 100,000 population, by sex, Great Britain. 2013. http://www.cancerresearchuk. 
org/sites/default/files/cstream-node/inc_asr_gb_nhl_ 1.pdf. Accessed 21 Jun 2017.

7. National Cancer Institute. Surveillance, Epidemiology, and End Results Program. Cancer Stat Facts: Non-Hodgkin Lymphoma. 2017. http://seer.cancer. gov/statfacts/html/nhl.html. Accessed 21 Jun 2017.

8. Chen Q, Jain N, Ayer T, et al. Economic burden of chronic lymphocytic leukemia in the era of oral targeted therapies in the United States. J Clin Oncol. 2017;35:166-74.

9. Tilly H, Gomes da Silva M, Vitolo U, et al. Diffuse large B-cell lymphoma (DLBCL): ESMO clinical practice guidelines for diagnosis, treatment and follow-up. Ann Oncol. 2015;26(Suppl 5):v116-25.

10. Dreyling M, Ghielmini M, Rule S, et al. Newly diagnosed and relapsed follicular lymphoma: ESMO clinical practice guidelines for diagnosis, treatment and follow-up. Ann Oncol. 2016;27(Suppl 5):v83-90.

11. Eichhorst B, Robak T, Montserrat E, et al. Chronic lymphocytic leukaemia: ESMO clinical practice guidelines for diagnosis, treatment and follow-up. Ann Oncol. 2015;26(Suppl 5):v78-84.

12. Hoster E, Dreyling M, Klapper W, et al. A new prognostic index (MIPI) for patients with advanced-stage mantle cell lymphoma. Blood. 2008;111:558-65.

13. International CLL-IPI Working Group. An international prognostic index for patients with chronic lymphocytic leukaemia (CLL-IPI): a meta-analysis of individual patient data. Lancet Oncol. 2016;17:779-90.

14. Lenz G, Wright GW, Emre NC, et al. Molecular subtypes of diffuse large B-cell lymphoma arise by distinct genetic pathways. Proc Natl Acad Sci U S A. 2008;105:13520-5.

15. Scott DW, Mottok A, Ennishi D, et al. Prognostic significance of diffuse large B-cell lymphoma cell of origin determined by digital gene expression in formalin-fixed paraffin-embedded tissue biopsies. J Clin Oncol. 2015;33:2848-56.

16. Köhler G, Milstein C. Continuous cultures of fused cells secreting antibody of predefined specificity. Nature. 1975;256:495-7.

17. National Cancer Institute. Using the immune system in the fight against cancer: discovery of rituximab. 2014. http://www.cancer.gov/research/progress/ discovery/blood-cancer. Accessed 21 Jun 2017.

18. Nadler LM, Stashenko P, Hardy R, et al. Serotherapy of a patient with a monoclonal antibody directed against a human lymphoma-associated antigen. Cancer Res. 1980;40:3147-54.

19. Miller RA, Maloney DG, Warnke R, Levy R. Treatment of B-cell lymphoma with monoclonal anti-idiotype antibody. $\mathrm{N}$ Engl J Med. 1982;306:517-22.

20. Press OW, Appelbaum F, Ledbetter JA, et al. Monoclonal antibody 1F5 (anti-CD20) serotherapy of human B cell lymphomas. Blood. 1987;69:584-91.

21. Banchereau J, Rousset F. Human B lymphocytes: phenotype, proliferation, and differentiation. Adv Immunol. 1992;52:125-262.

22. National Comprehensive Cancer Network. NCCN clinical practice guidelines in oncology. B-cell lymphomas. Version 3.2016. 2016. http://www. nccn.org/professionals/physician_gls/f_guidelines. asp\#site. Accessed 21 Jun 2017.

23. National Comprehensive Cancer Network. NCCN clinical practice guidelines in oncology. Chronic lymphocytic leukemia/small lymphocytic lymphoma. Version 1.2017. 2017. http://www.nccn.org/ professionals/physician_gls/f_guidelines.asp\#site. Accessed 21 Jun 2017.

24. World Health Organization. WHO Model Lists of Essential Medicines, adults. 20th edn. 2017. http://www.who.int/medicines/publications/essentialmedicines/en/. Accessed 21 Jun 2017.

25. Davies A, Merli F, Mihaljevic B, et al. Pharmacokinetics and safety of subcutaneous rituximab in follicular lymphoma (SABRINA): stage 1 analysis of a randomised phase 3 study. Lancet Oncol. 2014;15:343-52.

26. Assouline S, Buccheri V, Delmer A, et al. Pharmacokinetics, safety, and efficacy of subcutaneous versus intravenous rituximab plus chemotherapy as treatment for chronic lymphocytic leukaemia (SAWYER): a phase 1b, open-label, randomised controlled non-inferiority trial. Lancet Haematol. 2016;3:e128-38.

27. Dreyling M, Geisler C, Hermine O, et al. Newly diagnosed and relapsed mantle cell lymphoma: ESMO clinical practice guidelines for diagnosis, treatment and follow-up. Ann Oncol. 2014;25(Suppl 3):iii83-92.

28. Lopez-Olivo MA, Amezaga Urruela M, McGahan L, Pollono EN, Suarez-Almazor ME. Rituximab for rheumatoid arthritis. Cochrane Database Syst Rev. 2015;1:CD007356.

29. Mabthera $100 \mathrm{mg}$ concentrate for solution for infusion [summary of product characteristics]. Roche Products, Welwyn Garden City. 2017. 
https://www.medicines.org.uk/emc/medicine/2570. Accessed 18 Sept 2017.

30. Rituxan ${ }^{\circledR}$ (rituximab) injection, for intravenous use. Genentech, South San Francisco. 2016. https:// www.gene.com/download/pdf/rituxan_prescribing. pdf. Accessed 21 Jun 2017.

31. Davies A, Berge C, Boehnke A, et al. Subcutaneous rituximab for the treatment of B-cell hematological malignancies: scientific rationale and clinical development. Adv Ther. 2017.

32. Reff ME, Carner K, Chambers KS, et al. Depletion of $B$ cells in vivo by a chimeric mouse human monoclonal antibody to CD20. Blood. 1994;83:435-45.

33. Maloney DG, Smith B, Rose A. Rituximab: mechanism of action and resistance. Semin Oncol. 2002;29(1 Suppl 2):2-9.

34. Weiner GJ. Rituximab: mechanism of action. Semin Hematol. 2010;47:115-23.

35. Boross P, Leusen JH. Mechanisms of action of CD20 antibodies. Am J Clin Res. 2012;2:676-90.

36. Abulayha A, Bredan A, El Enshasy H, Daniels I. Rituximab: modes of action, remaining dispute and future perspective. Future Oncol. 2014;10:2481-92.

37. Weiner GJ, Bowles JA, Link BK, et al. Anti-CD20 monoclonal antibody (mAb) with enhanced affinity for CD16 activates NK cells at lower concentrations and more effectively than rituximab. Blood. 2005; $106: 348$.

38. Maloney DG, Liles TM, Czerwinski DK, et al. Phase I clinical trial using escalating single-dose infusion of chimeric anti-CD20 monoclonal antibody (IDEC-C2B8) in patients with recurrent B-cell lymphoma. Blood. 1994;84:2457-66.

39. Maloney DG, Grillo-López AJ, White CA, et al. IDEC-C2B8 (rituximab) anti-CD20 monoclonal antibody therapy in patients with relapsed low-grade non-Hodgkin's lymphoma. Blood. 1997;90:2188-95.

40. Berinstein NL, Grillo-López AJ, White CA, et al. Association of serum rituximab (IDEC-C2B8) concentration and anti-tumor response in the treatment of recurrent low-grade or follicular non-Hodgkin's lymphoma. Ann Oncol. 1998;9:995-1001.

41. Regazzi MB, Iacona I, Avanzini MA, et al. Pharmacokinetic behaviour of rituximab. A study of different schedules of administration for heterogenous clinical settings. Ther Drug Monit. 2005;27:785-92.

42. Tran L, Baars JW, Aarden L, Beijnen JH, Huitema AD. Pharmacokinetics of rituximab in patients with
CD20 positive B-cell malignancies. Hum Antib. 2010;19:7-13.

43. Blasco H, Chatelut E, Benz de Bretagne I, Congy-Jolivet N, Le Guellec C. Pharmacokinetics of rituximab associated with $\mathrm{CHOP}$ chemotherapy in B-cell non-Hodgkin lymphoma. Fundam Clin Pharmacol. 2009;23:601-8.

44. Li L, Levi M, Charoin J-E, et al. Rituximab exhibits a long half-life based on a population pharmacokinetic analysis in non-Hodgkin's lymphoma (NHL) patients. Blood. 2007;110:2371.

45. Li J, Zhi J, Wenger M, et al. Population pharmacokinetics of rituximab in patients with chronic lymphocytic leukemia. J Clin Pharmacol. 2012;52:1918-26.

46. Tobinai $\mathrm{K}$, Igarashi $\mathrm{T}$, Itoh $\mathrm{K}$, et al. Japanese multicenter phase II and pharmacokinetic study of rituximab in relapsed or refractory patients with aggressive B-cell lymphoma. Ann Oncol. 2004;15:821-30.

47. Daydé D, Ternant D, Ohresser M, et al. Tumor burden influences exposure and response to rituximab: pharmacokinetic-pharmacodynamic modeling using a syngeneic bioluminescent murine model expressing human CD20. Blood. 2009; 113:3765-72.

48. Igarashi T, Kobayashi Y, Ogura M, et al. Factors affecting toxicity, response and progression-free survival in relapsed patients with indolent B-cell lymphoma and mantle cell lymphoma treated with rituximab: a Japanese phase II study. Ann Oncol. 2002; 13:928-43.

49. Jäger $U$, Fridrik $M$, Zeitlinger $M$, et al. Rituximab serum concentrations during immuno-chemotherapy of follicular lymphoma correlate with patient gender, bone marrow infiltration and clinical response. Haematologica. 2012;97:1431-8.

50. Tout M, Casasnovas O, Meignan M, et al. Rituximab exposure is influenced by baseline metabolic tumor volume and predicts outcome of DLBCL patients: a Lymphoma Study Association report. Blood. 2017;129:2616-23.

51. Müller C, Murawski N, Wiesen MH, et al. The role of sex and weight on rituximab clearance and serum elimination half-life in elderly patients with DLBCL. Blood. 2012;119:3276-84.

52. Pfreundschuh M, Müller C, Zeynalova S, et al. Suboptimal dosing of rituximab in male and female patients with DLBCL. Blood. 2014;123:640-6.

53. Junlén HR, Peterson S, Kimby E, et al. Follicular lymphoma in Sweden: nationwide improved 
survival in the rituximab era, particularly in elderly women: a Swedish Lymphoma Registry study. Leukemia. 2015;29:668-76.

54. McLaughlin P, Grillo-López AJ, Link BK, et al. Rituximab chimeric anti-CD20 monoclonal antibody therapy for relapsed indolent lymphoma: half of patients respond to a four-dose treatment program. J Clin Oncol. 1998;16:2825-33.

55. Davis TA, White CA, Grillo-López AJ, et al. Single-agent monoclonal antibody efficacy in bulky non-Hodgkin's lymphoma: results of a phase II trial of rituximab. J Clin Oncol. 1999;17:1851-7.

56. Feuring-Buske M, Kneba M, Unterhalt $M$, et al. IDECC2B8 (rituximab) anti-CD20 antibody treatment in relapsed relapsed advanced-stage follicular lymphomas: results of a phase-II study of the German Low-Grade Lymphoma Study Group. Ann Hematol. 2000;79:493-500.

57. Foran JM, Gupta RK, Cunningham D, et al. A UK multicentre phase II study of rituximab (chimaeric anti-CD20 monoclonal antibody) in patients with follicular lymphoma, with PCR monitoring of molecular response. Br J Haematol. 2000;109:81-8.

58. Piro LD, White CA, Grillo-López AJ, et al. Extended rituximab (anti-CD20 monoclonal antibody) therapy for relapsed or refractory low-grade or follicular non-Hodgkin's lymphoma. Ann Oncol. 1999;10:655-61.

59. Colombat P, Brousse N, Salles G, et al. Rituximab induction immunotherapy for first-line low-tumor-burden follicular lymphoma: survival analyses with 7-year follow-up. Ann Oncol. 2012;23:2380-5.

60. Taverna C, Martinelli G, Hitz F, et al. Rituximab maintenance for a maximum of 5 years after single-agent rituximab induction in follicular lymphoma: results of the randomized controlled phase III trial SAKK 35/03. J Clin Oncol. 2016;34:495-500.

61. Kimby E, Ostenstad B, Brown P, et al. Two courses of four weekly infusions of rituximab with or without interferon- $\alpha 2 \mathrm{a}$ : final results from a randomized phase III study in symptomatic indolent B-cell lymphomas. Leuk Lymphoma. 2015;56:2598-607.

62. Czuczman MS, Weaver R, Alkuzweny B, et al. Prolonged clinical and molecular remission in patients with low-grade or follicular non-Hodgkin's lymphoma treated with rituximab plus CHOP chemotherapy: 9-year follow-up. J Clin Oncol. 2004;22:4711-6.

63. Hiddemann W, Kneba M, Dreyling M, et al. Frontline therapy with rituximab added to the combination of cyclophosphamide, doxorubicin, vincristine, and prednisone (CHOP) significantly improves the outcome for patients with advanced-stage follicular lymphoma compared with therapy with CHOP alone: results of a prospective randomized study of the German Low-Grade Lymphoma Study Group. Blood. 2005;106:3725-32.

64. Herold M, Haas A, Srock S, et al. Rituximab added to first-line mitoxantrone, chlorambucil, and prednisolone chemotherapy followed by interferon maintenance prolongs survival in patients with advanced follicular lymphoma: an East German Study Group hematology and oncology study. J Clin Oncol. 2007;25:1986-92.

65. Marcus R, Imrie K, Belch A, et al. CVP chemotherapy plus rituximab compared with CVP as first-line treatment for advanced follicular lymphoma. Blood. 2005;105:1417-23.

66. Marcus R, Imrie K, Solal-Celigny P, et al. Phase III study of R-CVP compared with cyclophosphamide, vincristine, and prednisone alone in patients with previously untreated advanced follicular lymphoma. J Clin Oncol. 2008;26:4579-86.

67. Salles G, Mounier N, de Guibert S, et al. Rituximab combined with chemotherapy and interferon in follicular lymphoma patients: results of the GELA-GOELAMS FL2000 study. Blood. 2008;112:4824-31.

68. Bachy E, Houot R, Morschhauser F, et al. Long-term follow-up of the FL2000 study comparing CHVP-interferon to CHVP-interferon plus rituximab in follicular lymphoma. Haematologica. 2013;98:1107-14.

69. Federico M, Luminari S, Dondi A, et al. R-CVP versus R-CHOP versus R-FM for the initial treatment of patients with advanced-stage follicular lymphoma: results of the FOLL05 trial conducted by the Fondazione Italiana Linfomi. J Clin Oncol. 2013;31:1506-13.

70. Rummel MJ, Niederle N, Maschmeyer G, et al. Bendamustine plus rituximab versus CHOP plus rituximab as first-line treatment for patients with indolent and mantle-cell lymphomas: an open-label, multicentre, randomised, phase 3 non-inferiority trial. Lancet. 2013;381:1203-10.

71. van Oers MH, Klasa R, Marcus RE, et al. Rituximab maintenance improves clinical outcome of relapsed/resistant follicular non-Hodgkin lymphoma in patients both with and without rituximab during induction: results of a prospective randomized phase 3 intergroup trial. Blood. 2006;108:3295-301.

72. Hochster H, Weller E, Gascoyne RD, et al. Maintenance rituximab after cyclophosphamide, vincristine, and prednisone prolongs progression-free 
survival in advanced indolent lymphoma: results of the randomized phase III ECOG1496 study. J Clin Oncol. 2009;27:1607-14.

73. Salles G, Seymour JF, Offner F, et al. Rituximab maintenance for 2 years in patients with high tumour burden follicular lymphoma responding to rituximab plus chemotherapy (PRIMA): a phase 3 , randomised controlled trial. Lancet. 2011;377:42-51.

74. Salles GA, Seymour JF, Feugier P, et al. Updated 6-year follow-up of the PRIMA study confirms the benefit of 2-year rituximab maintenance in follicular lymphoma patients responding to frontline immunochemotherapy. Blood. 2013;122:509.

75. Kahl BS, Hong F, Williams ME, et al. Rituximab extended schedule or re-treatment trial for low-tumor burden follicular lymphoma: Eastern Cooperative Oncology Group protocol E4402. J Clin Oncol. 2014;32:3096-102.

76. Forstpointner R, Dreyling M, Repp R, et al. The addition of rituximab to a combination of fludarabine, cyclophosphamide, mitoxantrone (FCM) significantly increases the response rate and prolongs survival as compared with FCM alone in patients with relapsed and refractory follicular and mantle cell lymphomas: results of a prospective randomized study of the German Low-Grade Lymphoma Study Group. Blood. 2004;104: 3064-71.

77. Forstpointner R, Unterhalt M, Dreyling M, et al. Maintenance therapy with rituximab leads to a significant prolongation of response duration after salvage therapy with a combination of rituximab, fludarabine, cyclophosphamide, and mitoxantrone (R-FCM) in patients with recurring and refractory follicular and mantle cell lymphomas: results of a prospective randomized study of the German Low Grade Lymphoma Study Group (GLSG). Blood. 2006;108:4003-8.

78. van Oers MH, Van Glabbeke M, Giurgea L, et al. Rituximab maintenance treatment of relapsed/ resistant follicular non-Hodgkin's lymphoma: longterm outcome of the EORTC 20981 phase III randomized intergroup study. J Clin Oncol. 2010;28:2853-8.

79. Martinelli G, Schmitz SF, Utiger U, et al. Long-term follow-up of patients with follicular lymphoma receiving single-agent rituximab at two different schedules in trial SAKK 35/98. J Clin Oncol. 2010;28:4480-4.

80. Vidal L, Gafter-Gvili A, Salles G, et al. Rituximab maintenance improves overall survival of patients with follicular lymphoma-Individual patient data meta-analysis. Eur J Cancer. 2017;76:216-25.
81. Hagemeister FB. 'Watch and wait' as initial management for patients with follicular lymphomas: still a viable strategy? BioDrugs. 2012;26:363-76.

82. Ardeshna KM, Qian W, Smith P, et al. Rituximab versus a watch-and-wait approach in patients with advanced-stage, asymptomatic, non-bulky follicular lymphoma: an open-label randomised phase 3 trial. Lancet Oncol. 2014;15:424-35.

83. Armitage JO, Longo DL. Is watch and wait still acceptable for patients with low-grade follicular lymphoma? Blood. 2016;127:2804-8.

84. Vose JM, Link BK, Grossbard ML, et al. Phase II study of rituximab in combination with $\mathrm{CHOP}$ chemotherapy in patients with previously untreated, aggressive non-Hodgkin's lymphoma. J Clin Oncol. 2001;19:389-97.

85. Coiffier B, Lepage E, Briere J, et al. CHOP chemotherapy plus rituximab compared with $\mathrm{CHOP}$ alone in elderly patients with diffuse large-B-cell lymphoma. N Engl J Med. 2002;346:235-42.

86. Habermann TM, Weller EA, Morrison VA, et al. Rituximab-CHOP versus $\mathrm{CHOP}$ alone or with maintenance rituximab in older patients with diffuse large B-cell lymphoma. J Clin Oncol. 2006;24:3121-7.

87. Pfreundschuh M, Trumper L, Osterborg A, et al. CHOP-like chemotherapy plus rituximab versus CHOP-like chemotherapy alone in young patients with good-prognosis diffuse large-B-cell lymphoma: a randomised controlled trial by the MabThera International Trial (MInT) Group. Lancet Oncol. 2006; 7:379-91.

88. Pfreundschuh M, Kuhnt E, Trumper L, et al. CHOP-like chemotherapy with or without rituximab in young patients with good-prognosis diffuse large-B-cell lymphoma: 6-year results of an open-label randomised study of the MabThera International Trial (MInT) Group. Lancet Oncol. 2011;12:1013-22.

89. Feugier P, Van Hoof A, Sebban C, et al. Long-term results of the R-CHOP study in the treatment of elderly patients with diffuse large B-cell lymphoma: a study by the Groupe d'Etude des Lymphomes de l'Adulte. J Clin Oncol. 2005;23:4117-26.

90. Coiffier B, Thieblemont C, Van Den Neste E, et al. Long-term outcome of patients in the LNH-98.5 trial, the first randomized study comparing rituximab-CHOP to standard CHOP chemotherapy in DLBCL patients: a study by the Groupe d'Etudes des Lymphomes de l'Adulte. Blood. 2010;116:2040-5.

91. Jaeger U, Trneny M, Melzer $H$, et al. Rituximab maintenance for patients with aggressive B-cell 
lymphoma in first remission: results of the randomized NHL13 trial. Haematologica. 2015;100:955-63.

92. Coiffier B, Haioun C, Ketterer N, et al. Rituximab (anti-CD20 monoclonal antibody) for the treatment of patients with relapsing or refractory aggressive lymphoma: a multicenter phase II study. Blood. 1998;92:1927-32.

93. Vellenga E, van Putten WLJ, van 't Veer MB, et al. Rituximab improves the treatment results of DHAP-VIM-DHAP and ASCT in relapsed/progressive aggressive CD20+ NHL: a prospective randomized HOVON trial. Blood. 2008;111:537-43.

94. Gisselbrecht C, Glass B, Mounier N, et al. Salvage regimens with autologous transplantation for relapsed large B-cell lymphoma in the rituximab era. J Clin Oncol. 2010;28:4184-90.

95. Jermann M, Jost LM, Taverna $C$, et al. Rituximab-EPOCH, an effective salvage therapy for relapsed, refractory or transformed B-cell lymphomas: results of a phase II study. Ann Oncol. 2004;15:511-6.

96. Kewalramani T, Zelenetz AD, Nimer SD, et al. Rituximab and ICE as second-line therapy before autologous stem cell transplantation for relapsed or primary refractory diffuse large B-cell lymphoma. Blood. 2004;103:3684-8.

97. Mey UJ, Olivieri A, Orlopp KS, et al. DHAP in combination with rituximab vs DHAP alone as salvage treatment for patients with relapsed or refractory diffuse large B-cell lymphoma: a matched-pair analysis. Leuk Lymphoma. 2006;47:2558-66.

98. Elstrom RL, Andemariam B, Martin P, et al. Bortezomib in combination with rituximab, dexamethasone, ifosfamide, cisplatin and etoposide chemo- immunotherapy in patients with relapsed and primary refractory diffuse large B-cell lymphoma. Leuk Lymphoma. 2012;53:1469-73.

99. Hallek M, Fischer K, Fingerle-Rowson G, et al. Addition of rituximab to fludarabine and cyclophosphamide in patients with chronic lymphocytic leukaemia: a randomised, open-label, phase 3 trial. Lancet. 2010;376:1164-74.

100. Robak T, Dmoszynska A, Solal-Céligny $\mathrm{P}$, et al. Rituximab plus fludarabine and cyclophosphamide prolongs progression-free survival compared with fludarabine and cyclophosphamide alone in previously treated chronic lymphocytic leukemia. J Clin Oncol. 2010;28:1756-65.

101. Byrd JC, Murphy T, Howard RS, et al. Rituximab using a thrice weekly dosing schedule in B-cell chronic lymphocytic leukemia and small lymphocytic lymphoma demonstrates clinical activity and acceptable toxicity. J Clin Oncol. 2001;19:2153-64.

102. O'Brien SM, Kantarjian H, Thomas DA, et al. Rituximab dose-escalation trial in chronic lymphocytic leukemia. J Clin Oncol. 2001;19:2165-70.

103. Schulz H, Klein SK, Rehwald U, et al. Phase 2 study of a combined immunochemotherapy using rituximab and fludarabine in patients with chronic lymphocytic leukemia. Blood. 2002;100:3115-20.

104. Byrd JC, Peterson BL, Morrison VA, et al. Randomized phase 2 study of fludarabine with concurrent versus sequential treatment with rituximab in symptomatic, untreated patients with B-cell chronic lymphocytic leukemia: results from Cancer and Leukemia Group B 9712 (CALGB 9712). Blood. 2003;101:6-14.

105. Keating MJ, O’Brien S, Albitar M, et al. Early results of a chemoimmunotherapy regimen of fludarabine, cyclophosphamide, and rituximab as initial therapy for chronic lymphocytic leukemia. J Clin Oncol. 2005;23:4079-88.

106. Wierda W, O'Brien S, Wen S, et al. Chemoimmunotherapy with fludarabine, cyclophosphamide, and rituximab for relapsed and refractory chronic lymphocytic leukemia. J Clin Oncol. 2005;23:4070-8.

107. Fischer K, Bahlo J, Fink AM, et al. Long-term remissions after FCR chemoimmunotherapy in previously untreated patients with CLL: updated results of the CLL8 trial. Blood. 2016;127:208-15.

108. Rossi D, Terzi-di-Bergamo L, De Paoli L, et al. Molecular prediction of durable remission after first-line fludarabine-cyclophosphamide-rituximab in chronic lymphocytic leukemia. Blood. 2015;126:1921-4.

109. Thompson P, Tam CS, O'Brien SM, et al. Fludarabine, cyclophosphamide, and rituximab treatment achieves long-term disease-free survival in IGHV-mutated chronic lymphocytic leukemia. Blood. 2016;127:303-9.

110. Tam CS, O'Brien S, Wierda W, et al. Long-term results of the fludarabine, cyclophosphamide, and rituximab regimen as initial therapy of chronic lymphocytic leukemia. Blood. 2008;112:975-80.

111. Foon KA, Boyiadzis M, Land SR, et al. Chemoimmunotherapy with low-dose fludarabine and cyclophosphamide and high-dose rituximab in previously untreated patients with chronic lymphocytic leukemia. J Clin Oncol. 2009;27:498-503.

112. Foon KA, Mehta D, Lentzsch S, et al. Long-term results of chemoimmunotherapy with low-dose 
fludarabine, cyclophosphamide and high-dose rituximab as initial treatment for patients with chronic lymphocytic leukemia. Blood. 2012;119:3184-5.

113. Woyach JA, Ruppert AS, Heerema NA, et al. Chemoimmunotherapy with fludarabine and rituximab produces extended overall survival and progression-free survival in chronic lymphocytic leukemia: long-term follow-up of CALGB study 9712. J Clin Oncol. 2011;29:1349-55.

114. Fischer K, Cramer P, Busch R, et al. Bendamustine combined with rituximab in patients with relapsed and/or refractory chronic lymphocytic leukemia: a multicenter phase II trial of the German Chronic Lymphocytic Leukemia Study Group. J Clin Oncol. 2011;29:3559-66.

115. Fischer K, Cramer P, Busch R, et al. Bendamustine in combination with rituximab for previously untreated patients with chronic lymphocytic leukemia: a multicenter phase II trial of the German Chronic Lymphocytic Leukemia Study Group. J Clin Oncol. 2012;30:3209-16.

116. Eichhorst B, Fink AM, Bahlo J, et al. First-line chemoimmunotherapy with bendamustine and rituximab versus fludarabine, cyclophosphamide, and rituximab in patients with advanced chronic lymphocytic leukaemia (CLL10): an international, open-label, randomised, phase 3, non-inferiority trial. Lancet Oncol. 2016;17:928-42.

117. Foà R, Del Giudice I, Cuneo A, et al. Chlorambucil plus rituximab with or without maintenance rituximab as first-line treatment for elderly chronic lymphocytic leukemia patients. Am J Hematol. 2014;89:480-6.

118. Hillmen P, Gribben JG, Follows GA, et al. Rituximab plus chlorambucil as first-line treatment for chronic lymphocytic leukemia: final analysis of an open-label phase II study. J Clin Oncol. 2014;32:1236-41.

119. Del Poeta G, Del Principe MI, Buccisano F, et al. Consolidation and maintenance immunotherapy with rituximab improve clinical outcome in patients with B-cell chronic lymphocytic leukemia. Cancer. 2008;112:119-28.

120. Abrisqueta P, Villamor N, Terol MJ, et al. Rituximab maintenance after first-line therapy with rituximab, fludarabine, cyclophosphamide, and mitoxantrone (R-FCM) for chronic lymphocytic leukemia. Blood. 2013;122:3951-9.

121. Dartigeas C, van den Neste E, Maisonneuve H, et al. Rituximab maintenance after induction with abbreviated FCR in previously untreated elderly ( $\geq 65$ years) CLL patients: results of the randomized CLL 2007 SA trial from the French FILO Group (NCT00645606). J Clin Oncol. 2016;34(15 Suppl):7505.

122. Awan FT, Gore L, Gao L, Sharma J, Lager J, Costa LJ. Phase Ib trial of the PI3K/mTOR inhibitor voxtalisib (SAR245409) in combination with chemoimmunotherapy in patients with relapsed or refractory B-cell malignancies. Br J Haematol. 2016;175:55-65.

123. Chanan-Khan A, Cramer P, Demirkan F, et al. Ibrutinib combined with bendamustine and rituximab compared with placebo, bendamustine, and rituximab for previously treated chronic lymphocytic leukaemia or small lymphocytic lymphoma (HELIOS): a randomised, double-blind, phase 3 study. Lancet Oncol. 2016;17:200-11.

124. Kipps TJ, Eradat H, Grosicki S, et al. A phase 2 study of the BH3 mimetic BCL2 inhibitor navitoclax (ABT-263) with or without rituximab, in previously untreated B-cell chronic lymphocytic leukemia. Leuk Lymphoma. 2015;56:2826-33.

125. Del Poeta G, Postorino M, Pupo L, et al. Venetoclax: Bcl-2 inhibition for the treatment of chronic lymphocytic leukemia. Drugs Today. 2016;52:249-60.

126. Zucca E, Conconi A, Martinelli G, et al. Final results of the IELSG-19 randomized trial of mucosa-associated lymphoid tissue lymphoma: improved event-free and progression-free survival with rituximab plus chlorambucil versus either chlorambucil or rituximab monotherapy. J Clin Oncol. 2017;35:1905-12.

127. Williams ME, Hong F, Gascoyne RD, et al. Rituximab extended schedule or retreatment trial for low tumour burden non-follicular indolent B-cell non-Hodgkin lymphomas: Eastern Cooperative Oncology Group protocol E4402. Br J Haematol. 2016;173:867-75.

128. Maury S, Chevret S, Thomas X, et al. Rituximab in B-lineage adult acute lymphoblastic leukemia. N Engl J Med. 2016;375:1044-53.

129. Ribrag V, Koscielny S, Bosq J, et al. Rituximab and dose-dense chemotherapy for adults with Burkitt's lymphoma: a randomised, controlled, open-label, phase 3 trial. Lancet. 2016;387:2402-11.

130. Griffiths R, Mikhael J, Gleeson M, et al. Addition of rituximab to chemotherapy alone as first-line therapy improves overall survival in elderly patients with mantle cell lymphoma. Blood. 2011;118:4808-16.

131. Kluin-Nelemans HC, Hoster E, Hermine O, et al. Treatment of older patients with mantle-cell lymphoma. N Engl J Med. 2012;367:520-31.

132. Dimopoulos MA, Anagnostopoulos A, Kyrtsonis $\mathrm{MC}$, et al. Primary treatment of Waldenström 
macroglobulinemia with dexamethasone, rituximab, and cyclophosphamide. J Clin Oncol. 2007;25:3344-9.

133. Oki Y, Pro B, Fayad LE, et al. Phase 2 study of gemcitabine in combination with rituximab in patients with recurrent or refractory Hodgkin lymphoma. Cancer. 2008;112:831-6.

134. Trappe RU, Dierickx D, Zimmermann $H$, et al. Response to rituximab induction is a predictive marker in B-cell post-transplant lymphoproliferative disorder and allows successful stratification into rituximab or R-CHOP consolidation in an international, prospective, multicenter phase II trial. J Clin Oncol. 2016. doi:10.1200/JCO.2016.69.3564.

135. Davis TA, Grillo-López AJ, White CA, et al. Rituximab anti-CD20 monoclonal antibody therapy in non-Hodgkin's lymphoma: safety and efficacy of re-treatment. J Clin Oncol. 2000;18:3135-43.

136. Rezvani AR, Maloney DG. Rituximab resistance. Best Pract Res Clin Haematol. 2011;24:203-16.

137. Bonavida B. Postulated mechanisms of resistance of B-cell non-Hodgkin lymphoma to rituximab treatment regimens: strategies to overcome resistance. Semin Oncol. 2014;41:667-77.

138. Czuczman MS, Olejniczak S, Gowda A, et al. Acquirement of rituximab resistance in lymphoma cell lines is associated with both global CD20 gene and protein down-regulation regulated at the pretranscriptional and posttranscriptional levels. Clin Cancer Res. 2008;14:1561-70.

139. Hiraga J, Tomita A, Sugimoto T, et al. Down-regulation of CD20 expression in B-cell lymphoma cells after treatment with rituximab-containing combination chemotherapies: its prevalence and clinical significance. Blood. 2009;113:4885-93.

140. Beum PV, Peek EM, Lindorfer MA, et al. Loss of CD20 and bound CD20 antibody from opsonized B cells occurs more rapidly because of trogocytosis mediated by Fc receptor-expressing effector cells than direct internalization by the $\mathrm{B}$ cells. J Immunol. 2011;187:3438-47.

141. Badoux XC, Keating MJ, Wen S, et al. Phase II study of lenalidomide and rituximab as salvage therapy for patients with relapsed or refractory chronic lymphocytic leukemia. J Clin Oncol. 2013;31:584-91.

142. Ivanov V, Coso D, Chetaille B, et al. Efficacy and safety of lenalidomide combined with rituximab in patients with relapsed/refractory diffuse large B-cell lymphoma. Leuk Lymphoma. 2014;55:2508-13.

143. Chong EA, Ahmadi T, Aqui NA, et al. Combination of lenalidomide and rituximab overcomes rituximab resistance in patients with indolent B-cell and mantle cell lymphomas. Clin Cancer Res. 2015;21:1835-42.

144. Leonard JP, Jung SH, Johnson J, et al. Randomized trial of lenalidomide alone versus lenalidomide plus rituximab in patients with recurrent follicular lymphoma: CALGB 50401 (Alliance). J Clin Oncol. 2015;33:3635-40.

145. Gazyvaro ${ }^{\circledR} 1000 \mathrm{mg}$ concentrate for solution for infusion [summary of product characteristics]. Roche Products, Welwyn Garden City. 2016. http://www. medicines.org.uk/emc/medicine/29057. Accessed 1 Jun 2017.

146. Minard-Colin V, Auperin A, Pillon M, et al. Results of the randomized Intergroup trial Inter-B-NHL Ritux 2010 for children and adolescents with high-risk B-cell non-Hodgkin lymphoma (B-NHL) and mature acute leukemia (B-AL): evaluation of rituximab (R) efficacy in addition to standard LMB chemotherapy (CT) regimen. J Clin Oncol. 2016;34(15 Suppl):10507.

147. Deconinck E, Miadi-Fargier H, Pen CL, Brice P. Cost effectiveness of rituximab maintenance therapy in follicular lymphoma: long-term economic evaluation. Pharmacoeconomics. 2010;28:35-46.

148. Ray JA, Carr E, Lewis G, Marcus R. An evaluation of the cost-effectiveness of rituximab in combination with chemotherapy for the first-line treatment of follicular non-Hodgkin's lymphoma in the UK. Value Health. 2010;13:346-57.

149. Soini EJ, Martikainen JA, Nousiainen T. Treatment of follicular non-Hodgkin's lymphoma with or without rituximab: cost-effectiveness and value of information based on a 5-year follow-up. Ann Oncol. 2011;22:1189-97.

150. Griffiths RI, Gleeson ML, Mikhael J, Danese MD. Impact on medical cost, cumulative survival, and cost-effectiveness of adding rituximab to first-line chemotherapy for follicular lymphoma in elderly patients: an observational cohort study based on SEER-Medicare. J Cancer Epidemiol. 2012;2012:978391.

151. Hornberger J, Chien R, Friedmann $M$, et al. Cost-effectiveness of rituximab as maintenance therapy in patients with follicular non-Hodgkin lymphoma after responding to first-line rituximab plus chemotherapy. Leuk Lymphoma. 2012;53:2371-7.

152. Blommestein HM, Issa DE, Pompen $\mathrm{M}$, et al. Cost-effectiveness of rituximab as maintenance treatment for relapsed follicular lymphoma: results of a population-based study. Eur J Haematol. 2014;92:398-406. 
153. Chen Q, Ayer T, Nastoupil LJ, Rose AC, Flowers CR. Comparing the cost-effectiveness of rituximab maintenance and radioimmunotherapy consolidation versus observation following first-line therapy in patients with follicular lymphoma. Value Health. 2015;18:189-97.

154. Prica A, Chan K, Cheung M. Frontline rituximab monotherapy induction versus a watch and wait approach for asymptomatic advanced-stage follicular lymphoma: a cost-effectiveness analysis. Cancer. 2015;121:2637-45.

155. Johnston KM, Marra CA, Connors JM, Najafzadeh M, Sehn L, Peacock SJ. Cost-effectiveness of the addition of rituximab to CHOP chemotherapy in first-line treatment for diffuse large B-cell lymphoma in a population-based observational cohort in British Columbia, Canada. Value Health. 2010;13:703-11.

156. Griffiths RI, Gleeson ML, Mikhael J, Dreyling MH, Danese MD. Comparative effectiveness and cost of adding rituximab to first-line chemotherapy for elderly patients diagnosed with diffuse large B-cell lymphoma. Cancer. 2012;118:6079-88.

157. Khor S, Beca J, Krahn M, et al. Real world costs and cost-effectiveness of rituximab for diffuse large B-cell lymphoma patients: a population-based analysis. BMC Cancer. 2014;14:586.

158. Hornberger J, Reyes C, Shewade A, et al. Cost-effectiveness of adding rituximab to fludarabine and cyclophosphamide for the treatment of previously untreated chronic lymphocytic leukemia. Leuk Lymphoma. 2012;53:225-34.

159. Adena M, Houltram J, Mulligan SP, Todd C, Malanos G. Modelling the cost effectiveness of rituximab in chronic lymphocytic leukaemia in first-line therapy and following relapse. Pharmacoeconomics. 2014;32:193-207.

160. Mandrik O, Corro Ramos I, Knies S, Al M, Severens JL. Cost-effectiveness of adding rituximab to fludarabine and cyclophosphamide for treatment of chronic lymphocytic leukemia in Ukraine. Cancer Manag Res. 2015;7:279-89.

161. Müller D, Fischer K, Kaiser P, et al. Cost-effectiveness of rituximab in addition to fludarabine and cyclophosphamide (R-FC) for the first-line treatment of chronic lymphocytic leukemia. Leuk Lymphoma. 2016;57:1130-9.

162. Danese MD, Reyes CM, Gleeson ML, Halperin M, Skettino SL, Mikhael J. Estimating the population benefits and costs of rituximab therapy in the United States from 1998 to 2013 using real-world data. Med Care. 2016;54:343-9.

163. Tobinai K, Klein C, Oya N, Fingerle-Rowson G. A review of obinutuzumab (GA101), a novel type II anti-CD20 monoclonal antibody, for the treatment of patients with B-cell malignancies. Adv Ther. 2017;34:324-56.

164. Goede V, Klein C, Stilgenbauer S. Obinutuzumab (GA101) for the treatment of chronic lymphocytic leukemia and other B-cell non-Hodgkin's lymphomas: a glycoengineered type II CD20 antibody. Oncol Res Treat. 2015;38:185-92.

165. Cang S, Mukhi N, Wang K, Liu D. Novel CD20 monoclonal antibodies for lymphoma therapy. J Hematol Oncol. 2012;5:64.

166. Jaglowski SM, Alinari L, Lapalombella R, et al. The clinical application of monoclonal antibodies in chronic lymphocytic leukemia. Blood. 2010;116:3705-14. 